REVIEW ARTICLE

\title{
Novel amidines and analogues as promising agents against intracellular parasites: a systematic review
}

\author{
M. N. C. SOEIRO ${ }^{1}$, K. WERBOVETZ ${ }^{2}$, D. W. BOYKIN ${ }^{3}$, W. D. WILSON ${ }^{3}$, M. Z. WANG \\ and $\mathrm{A}$. HEMPHILL ${ }^{5}$ \\ ${ }^{1}$ Laboratório de Biologia Celular, Instituto Oswaldo Cruz, Fundação Oswaldo Cruz, Rio de Faneiro, Brazil \\ ${ }^{2}$ Division of Medicinal Chemistry and Pharmacognosy, College of Pharmacy, The Ohio State University, Columbus, \\ OH 43210, USA \\ ${ }^{3}$ Department of Chemistry, Georgia State University, Atlanta, GA 30302, USA \\ ${ }^{4}$ Department of Pharmaceutical Chemistry, The University of Kansas, Lawrence, KS 66047, USA \\ ${ }^{5}$ Institute of Parasitology, Vetsuisse Faculty of Veterinary Medicine, University of Berne, Berne, Switzerland
}

(Received 29 November 2012; revised 22 Fanuary and 22 February 2013; accepted 1 March 2013; first published online 8 April 2013)

\begin{abstract}
SUMMARY
Parasitic protozoa comprise diverse aetiological agents responsible for important diseases in humans and animals including sleeping sickness, Chagas disease, leishmaniasis, malaria, toxoplasmosis and others. They are major causes of mortality and morbidity in tropical and subtropical countries, and are also responsible for important economic losses. However, up to now, for most of these parasitic diseases, effective vaccines are lacking and the approved chemotherapeutic compounds present high toxicity, increasing resistance, limited efficacy and require long periods of treatment. Many of these parasitic illnesses predominantly affect low-income populations of developing countries for which new pharmaceutical alternatives are urgently needed. Thus, very low research funding is available. Amidine-containing compounds such as pentamidine are DNA minor groove binders with a broad spectrum of activities against human and veterinary pathogens. Due to their promising microbicidal activity but their rather poor bioavailability and high toxicity, many analogues and derivatives, including pro-drugs, have been synthesized and screened in vitro and in vivo in order to improve their selectivity and pharmacological properties. This review summarizes the knowledge on amidines and analogues with respect to their synthesis, pharmacological profile, mechanistic and biological effects upon a range of intracellular protozoan parasites. The bulk of these data may contribute to the future design and structure optimization of new aromatic dicationic compounds as novel antiparasitic drug candidates.
\end{abstract}

Key words: intracellular parasites, chemotherapy, aromatic amidines, arylimidamides.

\section{INTRODUCTION}

Protozoan parasites cause a wide range of infectious diseases of medical and veterinary importance, and thus represent a major economic burden worldwide. Prevention and chemotherapy are two routes that are tracked to combat parasitic diseases. However, despite the fact that considerable efforts have been undertaken, not a single vaccine against a parasitic infection in humans has been marketed to date, and only a few have been commercialized for veterinary application, most of them live-attenuated vaccines. Thus, chemotherapeutic treatment still remains the sole option. Most drugs that are currently in use to combat parasitic infections were discovered decades ago, and development of resistance poses a major threat (Mäser et al. 2012). Chemotherapy is a viable choice, if potent, safe and inexpensive drugs are

* Corresponding author: Laboratório de Biologia Celular, Instituto Oswaldo Cruz, Fundação Oswaldo Cruz, Rio de Janeiro, Brazil. E-mail: soeiro@ioc.fiocruz.br made available, which are also easily administered, preferentially interfering in more than just one stage of the parasite life cycle and exhibiting selective toxicity (Delves et al. 2012). Thus, candidate compounds must be thoroughly characterized with regard to their mechanisms of action and potential targets.

Intracellular protozoan parasites, especially the trypanosomatids (e.g. Leishmania, Trypanosoma cruzi) and the apicomplexans (e.g. Plasmodium and Toxoplasma among others), have a significant socioeconomic impact worldwide. Their pathogenesis is related to the intracellular stages of their life cycle. This means that any compound targeted to kill these parasites must first cross the host cell membrane, then the parasitophorous vacuole membrane (relevant for most, but not all species), followed by the parasite plasmalemma, and finally also membranes of the organelle containing the relevant target(s). If the pathogen infects the CNS, the blood-brain barrier represents a further obstacle. Not surprisingly, the 
treatment options for diseases caused by these parasites are still limited, despite recent advances in some areas (Mäser et al. 2012).

In this review, we will focus on the design, synthesis, pharmacology and the mechanisms of action of amidine compounds and analogues (essentially derivatives of the broad-spectrum drug pentamidine) upon a range of intracellular protozoan parasites causing important diseases in animals and man, including Leishmania, T. cruzi, Plasmodium, Babesia, Toxoplasma, Neospora and Besnoitia.

\section{DESIGN AND SYNTHESIS}

Investigations into the antiprotozoan activity of classical aromatic diamidines (dicationic molecules Figs. 1-6) began over 7 decades ago with the pioneering work of Warrington Yorke (King et al. 1937). The early work led to the discovery that pentamidine (Fig. 1) and other aromatic diamidines were effective against human African trypanosomes (HAT) and some species of Leishmania (Ashley et al. 1942). Despite decades of extensive investigation into this class of compounds, pentamidine remains the only diamidine with significant clinical value and it is still used to treat antimonyresistant leishmaniasis, early stage Trypanosoma brucei gambiense HAT and Pneumocystis jiroveci infections (formerly Pneumocystis carinii) (Sands et al. 1985; Goa and Campoli-Richards, 1987; Barrett et al. 2003, 2007; Werbovetz, 2006; Singh et al. 2012). A limitation of pentamidine (and most diamidines) is that it must be administered parenterally due to its poor bioavailability attributable, in large part, to the high $\mathrm{p} K_{\mathrm{a}}$ of the amidine functional group (10-12).

In the last decade, pafuramidine (DB289, Fig. 3), an orally effective pro-drug of the diamidine furamidine (Fig. 1), was found to be effective against firststage HAT in a Phase III trial. Unfortunately, in a concurrent extended safety trial (Phase I) delayed renal toxicity was observed and the development of DB 289 was discontinued (Paine et al. 2010). Later (as will be detailed in the following sections), another class of amidines, initially described as 'reversed amidines' but now referred to as arylimidamides (Figs 1, 4 and 5), demonstrated high potency against several parasites like T. cruzi, Leishmania sp. (Stephens et al. 2003; Wang et al. 2010; Zhu et al. 2012), Neospora caninum (Debache et al. 2011; Schorer et al. 2012), Besnoitia besnoiti (Cortes et al. 2011) and Echinococcus multilocularis (Stadelmann et al. 2011). Arylimidamides (AIAs) have lower $\mathrm{p} K_{\mathrm{a}}$ values (7-8) than classical aromatic amidines and therefore generally exhibit better bioavailability (Wang et al. 2010). The mode of action of both classes of amidines remains to be rigorously determined (as will be further discussed in see section 'Mechanisms of antiparasitic action'). The two strands of the DNA double helix wrapped around each other creates two helical grooves, a wider, the major groove and a narrow one, the minor groove. The effectiveness of classical aromatic diamidines in recognizing the minor groove (space between the strands) of AT-rich sequences of DNA has led to a useful strategy for the design of new potential antiparasitic agents (Tidwell and Boykin 2003; Wilson et al. 2005, 2008; Nguyen et al. 2007). The beginning of a design paradigm for the targeting of the minor groove of DNA was clearly presented as early as the mid 1980s (Goodsell and Dickerson, 1986). Based on crystal structure data for known minor-groove binders such as netropsin, distamycin, Hoechst 33258 and related compounds, these authors concluded that the shape of the small molecule should be isohelical with the groove to which it was binding. Furthermore, the hydrogen bond acceptor and donors needed to be properly spaced to optimize the hydrogen-bonding interactions. Using these ideas J. W. Lown and co-workers developed a number of libraries of lexitropsin DNA minor-groove binders that were quite effective (Lown, 1994). These isohelical design ideas were expanded to aromatic diamidine analogues, including pentamidine, and were correlated with estimated radii of curvature for the small molecules (Cory et al. 1992). Thus for a number of years it was believed that a crescent-shaped small molecule was necessary to achieve higher binding affinity (Tidwell and Boykin, 2003). The near linear potent antitrypanosomal compound CGP 40215A (Fig. 1) was found to be a very strong minor-groove binder and the structure for a co-crystal with $\mathrm{d}$ (CGCGAATTCGCG) 2 showed that 2 water molecules participate in an indirect hydrogen bond between one of the amidine groups and a thymine carbonyl group (Nguyen et al. 2002, 2004). A study of the antitrypanosomal isomeric dicationic biphenylbenzimidazoles DB911 and DB921 (Fig. 1) provided another case to evaluate the necessity of small molecule-DNA groove shape complementarities (Ismail et al. 2004, 2005; Miao et al. 2005). In this pair DB911 has the classical crescent shape associated with the DNA minor groove whereas DB921 is a near-linear molecule, therefore it was a surprise that the DNA binding affinity to an A/T site for DB921 was 10-fold higher than that of DB911 (Miao et al. 2005). The structure of a DB921-d (CGCGAATTCGCG)2 co-crystal clearly showed that 1 water molecule forms a hydrogen bond array between the benzamidine group of DB921 and an adenine $\mathrm{N}$ atom (Miao et al. 2005). These examples show that water can mediate the interaction between linear dications and the DNA minor groove thus in effect providing an isohelical complex. Since water can serve as hydrogen bond isohelical mediators for linear dicationic molecules, such interactions should be taken into account in the 
<smiles>N=C(N)c1ccc(-c2ccc(-c3ccc(C(=N)N)cc3)o2)cc1</smiles>

furamidine (DB75)<smiles>N=C(N)c1ccc(OCCCCCOc2ccc(C(=N)N)cc2)cc1</smiles>

pentamidine<smiles>CC(C)(C)OC(=O)C(C)(C)C</smiles>

CGP 40215A

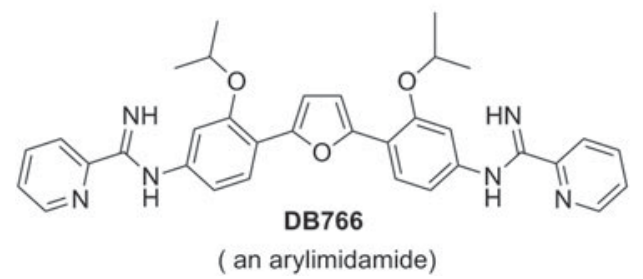<smiles>N=C(N)c1ccc(-c2cccc(-c3nc4ccc(C(=N)N)cc4[nH]3)c2)cc1</smiles><smiles>N=C(N)c1ccc(-c2ccc(-c3nc4ccc(C(=N)N)cc4[nH]3)cc2)cc1</smiles>

Fig. 1. Chemical structures of aromatic diamidines and arylimidamides.
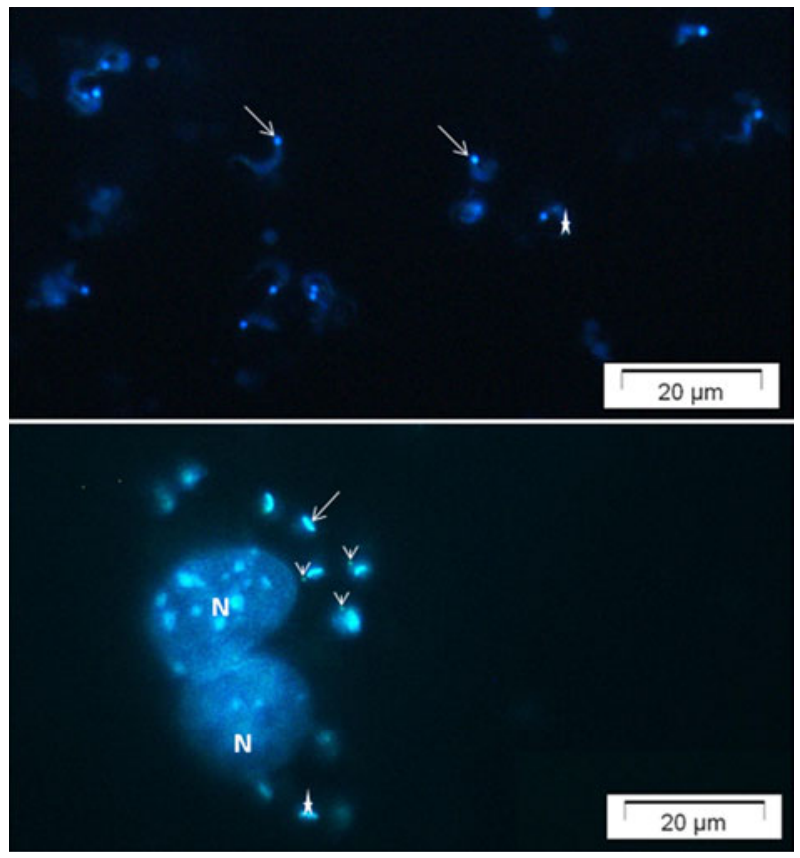

Fig. 2. Fluorescent microscopy of aromatic diamidine DB1582 (A) and DB1651 (B) staining of bloodstream trypomastigotes (A) and intracellular forms (B) of T. cruzi (Y strain). Parasites and infected-cardiac cell cultures were incubated for $60 \mathrm{~min}$ with $10 \mu \mathrm{g} \mathrm{mL} \mathrm{m}^{-1}$ DB1582 and DB1651. Note the dicationic compound in the parasite KDNA (arrow), nuclei (star) and within several non-DNA-containing organelles (arrowhead) distributed within the cytoplasm of intracellular amastigotes (acidocalcisomes-like structures). See host cell nuclei also labelled (N).

design of potential minor-groove binders. For a more detailed treatment of this subject see the review by Nguyen et al. (2007).
Aromatic diamidines are usually prepared from their corresponding bis-nitriles. In this review 3 major methods for achieving this conversion will be presented along with illustrations from the literature. The most venerable method for the nitrile to amidine conversion is known as the Pinner amidine synthesis which was first described by Pinner in 1877 (Pinner and Klein, 1877). This method, which is arguably the most widely used, has been reviewed by several authors (Shriner and Neumann, 1944; Roger and Neilson, 1961; Eloy and Lenaers, 1962; Aly and Nour-El-Din, 2008). Scheme 1 illustrates this 2-step process which was used in the synthesis of furamidine (Fig. 1) (Das and Boykin, 1977). The first step involves acid-catalysed addition of ethanol to the nitrile groups to form an imidate ester. The second step results in the formation of the amidine by the addition of ammonia or a wide array of amines; the latter gives this approach great versatility by allowing the generation of libraries of $N$-substituted amidines (Boykin et al. 1995). A major limitation of this method is that water must be rigorously excluded. A further complication is that aromatic bis-nitriles are frequently quite insoluble, which necessitates large volumes of solvent or long reaction times, either of which increase the possibility for exposure to water.

The second important method involves the intermediacy of amidoximes and is outlined in Scheme 2 (Judkins et al. 1996). This methodology was employed for the synthesis of highly active imidazo[1,2-a]pyridines (Ismail et al. 2004) and has been effectively employed in several other systems (Ismail et al. 2006, 2008, 2011). This process formally involves 3 steps; however, in practice the acetoxy analogue is not isolated, so functionally it is a 2 -step process. This method has the advantage that 
Diamidines<smiles>N=C(N)c1ccc(-c2ccc(-c3ccc(C(=N)N)cn3)o2)cc1</smiles>

DB820<smiles>N=C(N)c1ccc(-c2ccc(-c3ccc(C(=N)N)cn3)o2)nc1</smiles>

DB829<smiles>N=C(N)c1ccc(-c2cccc(-c3ccc(C(=N)N)nc3)c2)nc1</smiles>

Amidoximes<smiles>NC(=NO)c1ccc(-c2ccc(-c3ccc(C(N)=NO)cc3)o2)cc1</smiles>

DB290<smiles>NC(=NO)c1ccc(-c2ccc(-c3ccc(C(N)=NO)nc3)o2)cc1</smiles>

DB821<smiles>CCCCOC(=O)OCc1ccc(-c2ccc(-c3ccc(C(N)=NO)cn3)o2)nc1</smiles>

Methamidoximes<smiles>CON=C(N)c1ccc(-c2ccc(-c3ccc(C(N)=NOC)cc3)o2)cc1</smiles>

(DB289)<smiles>CON=C(N)c1ccc(-c2ccc(-c3ccc(C(N)=NOC)cc3)o2)cc1</smiles>

DB844<smiles>CON=C(N)c1ccc(-c2ccc(-c3ccc(C(N)=NOC)cn3)o2)nc1</smiles>

Fig. 3. Representative examples of diamidines, amidoximes, methamidoximes with some known pharmacokinetic properties.
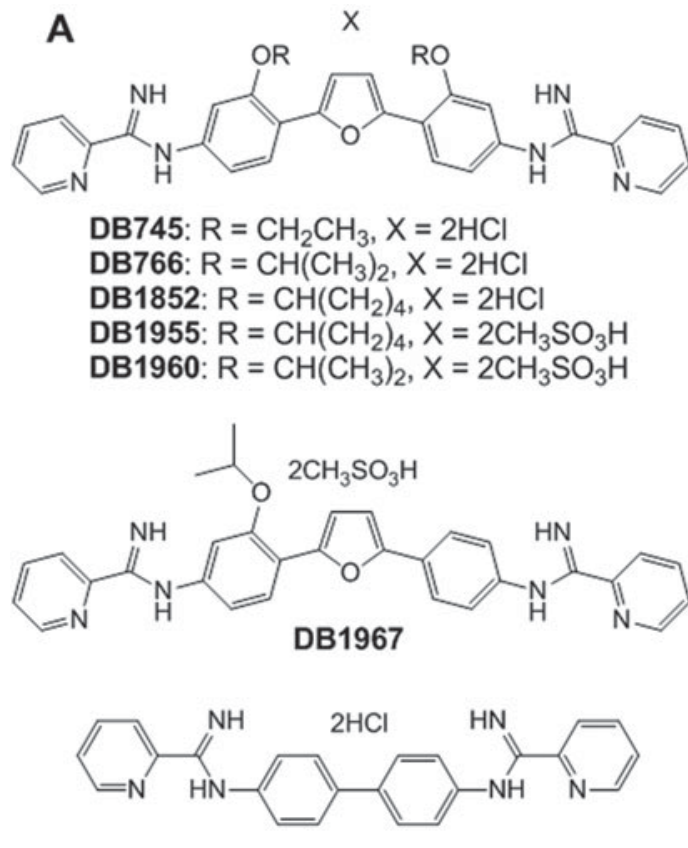

DB1832
B
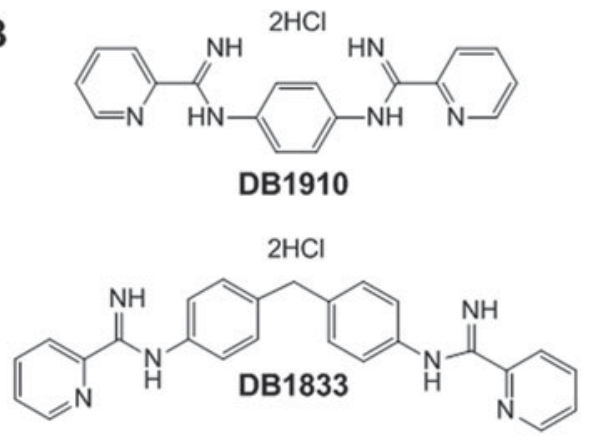<smiles>CCC(C)(C)c1ccc(-c2ccc(-c3ccc(NC(=N)c4ccccn4)o3)nc2)nc1</smiles><smiles>CC(C)(C)OCc1ccc(-c2ccc(-c3ccc(NC(=N)c4cnccn4)cc3)o2)cc1</smiles>

Fig. 4. Representative examples of AIAs tested against intracellular Leishmania. Panel A - Compounds possessing potent antileishmanial activity $\left(\mathrm{IC}_{50}\right.$ values $\left.<1 \mu \mathrm{M}\right)$. Panel $\mathrm{B}-$ Compounds that are inactive $\left(\mathrm{IC}_{50}\right.$ values $\left.>10 \mu \mathrm{M}\right)$.

rigorous water exclusion is not necessary. Unlike the Pinner process, $N$-substituted amidines cannot be made using this sequence. The presence of functional groups which can be reduced or cleaved under catalytic hydrogenation conditions and compounds that include sulphur-containing groups, which may poison the catalyst, reduce the flexibility of this method.

The third important method is clearly the most elegant and direct approach for conversion of nitriles into amidines and is shown in Scheme 3
(Boere et al. 1987). This approach was utilized in the preparation of the highly active naphthalenebiphenyl diamidine presented in Scheme 3 (ChackalCatoen et al. 2006) and has been extensively used in other systems (Hu et al. 2008, 2009; Farahat et al. 2010, 2011; Branowska et al. 2010; Ismail et al. 2011). This process involves the nucleophilic addition of a silyl protected amide anion to the nitrile group. The reaction is worked up with $\mathrm{HCl} / \mathrm{EtOH}$ which both de-protects the nitrogen atom and forms the hydrochloride salt of the amidine. This approach is limited 
<smiles>CC(C)Oc1cc(NC(=N)c2ncccn2)ccc1-c1ccc(-c2ccc(NC(=N)c3ncccn3)cc2OC(C)C)o1</smiles>

DB1831 hydrochloride salt DB1965 mesylate salt

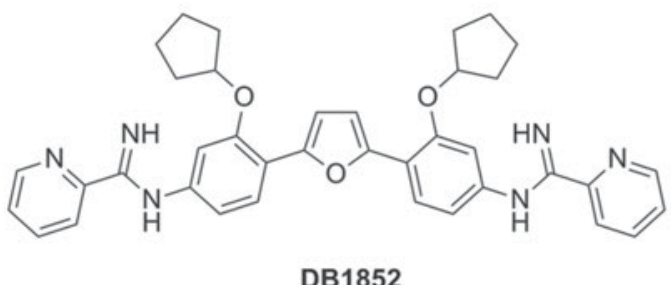

DB1852<smiles>N=C(Nc1ccc(-c2ccc(-c3ccc(NC(=N)c4ccccn4)cc3OCC(F)(F)F)o2)c(OCC(F)(F)F)c1)c1ccccn1</smiles>

DB1862<smiles>Cc1c(-c2ccc(C(=N)N)cc2)sc(-c2ccc(C(=N)N)cc2)c1Br</smiles>

DB1362<smiles>N=C(Nc1ccc(-c2ccc(-c3ccc(NC(=N)c4ncccn4)cc3OC3CCCC3)o2)c(OC2CCCC2)c1)c1ncccn1</smiles>

DB1853<smiles>CC(C)Oc1cc(NC(=N)c2ccccn2)ccc1-c1ccc(-c2ccc(NC(=N)c3ccccn3)cc2OC(C)C)s1</smiles>

DB1867<smiles>COc1ccc(C(=N)Nc2ccc(-c3ccc(-c4ccc(NC(=N)c5ccc(OC)cn5)cc4OC(C)C)o3)c(OC(C)C)c2)nc1</smiles>

DB1868

Fig. 5. Representative examples of amidines tested against Trypanosoma cruzi in in vitro and in vivo studies.

to preparation of unsubstituted amidines. If acidic hydrogen is present in a molecule that on deprotonation yields an anion that is in conjugation with the nitrile group, deactivation of the system to nucleophilic attack occurs, thus formation of the amidine often fails.

Bis-arylimidamides are readily prepared from bisnitro analogues as illustrated in Scheme 4 (Stephens et al. 2001; Wang et al. 2010). The iso-propoxy compound DB766 (Fig. 1) and its analogues were proved to be highly effective in animal models for intracellular obligatory parasites (Wang et al. 2010; Batista et al. 2010a,b; Da Silva et al. 2011a,b, 2012) The bis-nitro compounds can be reduced to the corresponding bis-amino analogues by either of two standard methods; catalytic hydrogenation or stannous chloride reduction. The target AIAs are readily obtained by reaction of the bis-amine with $S$-(2-naphthylmethyl)pyridine-2-carbimidothioate. The major limitation of this method is that a relatively basic amine is required as a substrate since bis-amines containing strong electron withdrawing groups fail to react (Stephens et al. 2001). Other synthetic approaches to these type AIAs have been reported (Hu and Boykin, 2009). Both classical diamidines and bis-arylimidamides are attractive candidates for use against various parasitic diseases; however for one to become useful it is essential that it is economical to synthesize. The synthesis of either class by one or more of the methods outlined in Schemes 1-4 are likely to be at a reasonable cost. The cost of synthesis for the required bis-nitrile or bisnitro precursor, however, can be quite variable and consideration should be given to linker selection early in the drug development process.

\section{MECHANISMS OF ANTIPARASITIC ACTION}

In spite of many years of study by a number of laboratories, it has proven surprisingly difficult to definitively establish a single mechanism of antiparasitic action of dications, and various targets have 


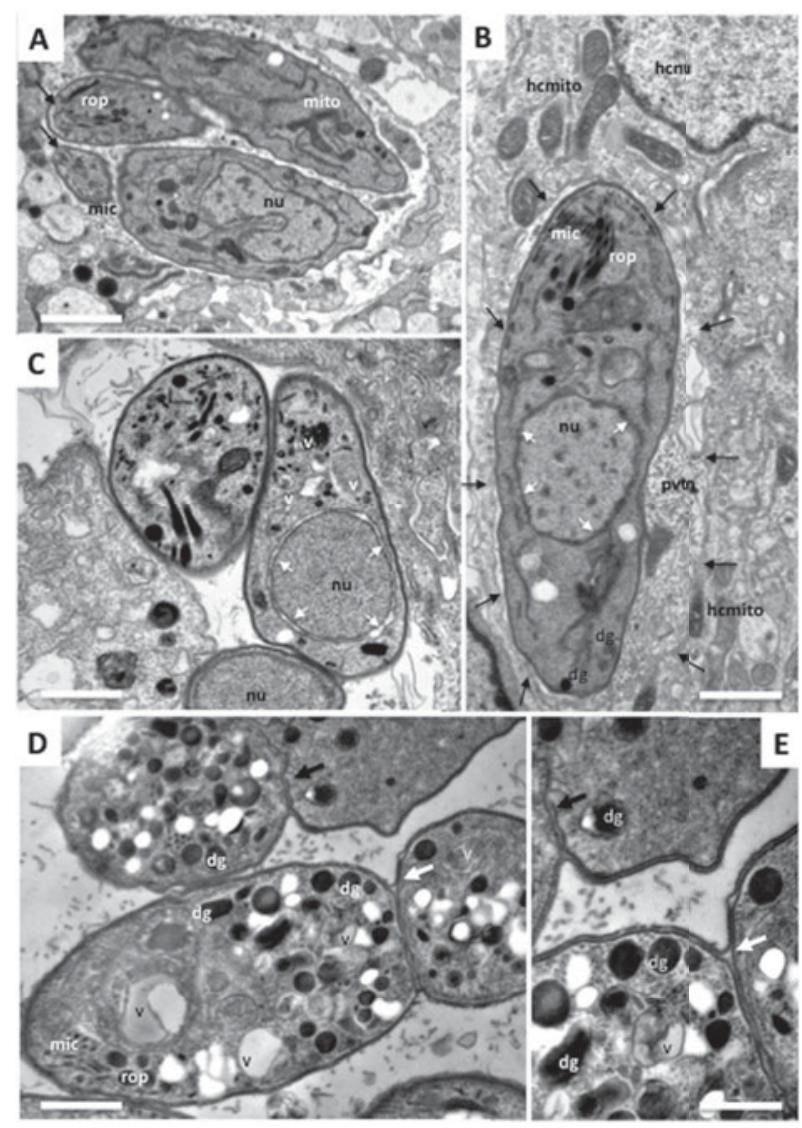

Fig. 6. Transmission electron microscopy of Neospora caninum tachyzoites cultured in the absence (A, B) and presence $(\mathrm{C}-\mathrm{E})$ of the arylimidamide DB745. (A) and (B) show control cultures at $48 \mathrm{~h}$ post-infection. Tachyzoites are situated within the cytoplasm and proliferate within a parasitophorous vacuole, surrounded by a

parasitophorous vacuole membrane (arrows in (B)). Rhoptries (rop), micronemes (mic), dense granules (dg), mitochondria (mito) and the nucleus (nuc) are visible. Arrows in (A) pointed to the conoid at the apical end of the parasites, while arrows in (B) indicate the parasitophorous vacuole membrane. The nuclei (nuc) contain electron-dense chromatin, and white arrows point to the intact nuclear membrane. Hcmito = host cell mitochondria, hcnuc $=$ host cell nucleus,

pvtn $=$ parasitophorous vacuole tubular network forming the matrix of the vacuole. Bar in (A) $=0.84 \mu \mathrm{m}$; bar in $(B)=0.55 \mu \mathrm{m}$. (C-E) represent images of tachyzoites after treatment with $1 \mu \mathrm{M} \mathrm{DB} 745$ for $24 \mathrm{~h}(\mathrm{C})$ and $48 \mathrm{~h}$ (D-E). In $(\mathrm{C})$, separated nuclear membranes are pointed out with white arrows. Cytoplasmic vacuoles (v) are partially filled with membranous and/or electron-dense material of unknown origin. Bar $=0.65 \mu \mathrm{m}$. (D) Tachyzoites after $48 \mathrm{~h}$ of culture but still fused together, showing increased vacuolization (v) and large numbers of dense granules (dg). (E) Higher magnification view of the fused contact sites shown in (D). Parasites are clearly separated by two distinct inner membranes, but held together by the outer plasma membrane. The black arrow indicates the blind ending of the inner membrane of the upper tachyzoite, the white arrow shows the contact site with the outer membrane fusing the parasites together. Bars in (D) $=0.4 \mu \mathrm{m}$; (E) $=0.25 \mu \mathrm{m}$. been suggested including both mitochondrial and nuclear DNA, microtubules, acidocalcisomes, and a range of enzymes ('Tidwell and Boykin, 2003; Arafa et al. 2005; Soeiro et al. 2005; Wilson et al. 2005, 2008; Werbovetz, 2006; Batista et al. 2010a,b; Paine et al. 2010; Ward et al. 2010). These compounds have typically been shown to selectively target AT-rich DNA and to form a complex in the minor groove of the double helix. This observation has led to considerable research to determine whether DNA is at least one of their cellular targets. Even for these fairly simple but structurally diverse compounds, however, it now seems certain that there is more than 1 bioreceptor in parasitic microorganisms. Both the mitochondrial and nuclear DNAs are well established as dication targets and the strongest evidence indicates that DNA functional destruction is related to their antiparasitic action (Wang and Englund, 2001; Soeiro et al. 2005, 2008; Wilson et al. 2005, 2008; Werbovetz, 2006; Soeiro and De Castro, 2009; Chowdhury et al. 2010). In trypanosomes, Leishmania and related organisms, the mitochondrial kinetoplast DNA (kDNA) network typically contains DNA minicircles that encode for guide RNAs that edit transcripts from the maxicircle DNA, which corresponds to the mitochondrial genome (Shapiro and Englund, 1995). The thousands of DNA minicircles are topologically linked in a planar disc array (Shapiro and Englund, 1995; Klingbeil et al. 2001), exhibiting, as does the genomic DNA of Plasmodium, greater AT content $(>75 \%)$, with extensive, closely spaced, sequences that act as strong binding sites and selective therapeutic target sites for these dicationic compounds (Carlton, 2003; Purfield et al. 2009).

The heterocyclic dications typically have absorption bands near 350-400 $\mathrm{nm}$ and emission bands in solution in the blue region near $450 \mathrm{~nm}$ (Wilson et al. 1990). By fluorescence (Fig. 2) and transmission electron microscopy analysis (Fig. 6), it is possible to follow the compound distribution and evaluate their ultrastructural effect on the treated parasites (Stewart et al. 2005; Lanteri et al. 2006; Werbovetz, 2006; Hu et al. 2008; Batista et al. 2010a,b). Results for a number of dications showed that they are first preferentially located in the kinetoplast and secondarily in the nucleus of Trypanosoma brucei, T. cruzi and Leishmania (Wang and Englund, 2001; Lanteri et al. 2006; Mathis et al. 2006, 2007; Batista et al. 2010a, 2010b; Chowdhury et al. 2010). The kDNA and kinetoplast itself are extensively modified shortly after treatment and the latter structure is generally destroyed about $24 \mathrm{~h}$ after diamidine exposure, leading to parasite death. In an important study, the Barrett group demonstrated that pentamidine targets the kinetoplast in Leishmania mexicana and that its concentration in the nucleus, cytoplasm and other cell compartments is very low (Basselin et al. 2002). In a strain of pentamidine-resistant $L$. mexicana 


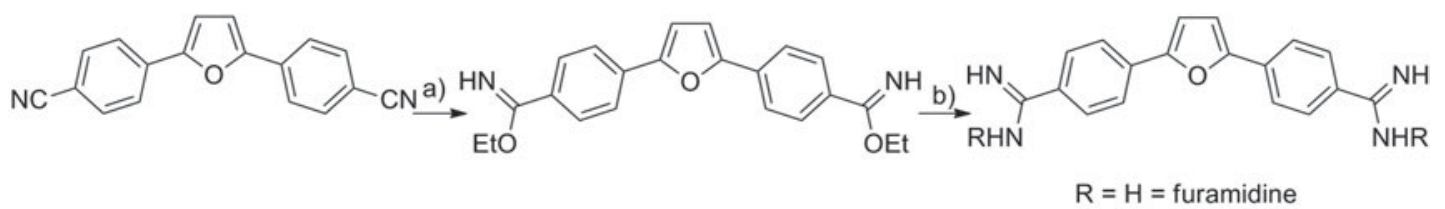

Reagents and Conditions: a) $\mathrm{HCl}(\mathrm{g}), \mathrm{EtOH}$ b) $\mathrm{NH}_{3}$ or $\mathrm{RNH}_{2}$, $\mathrm{EtOH}$

Scheme 1. Synthesis of furamidine by the Pinner method.

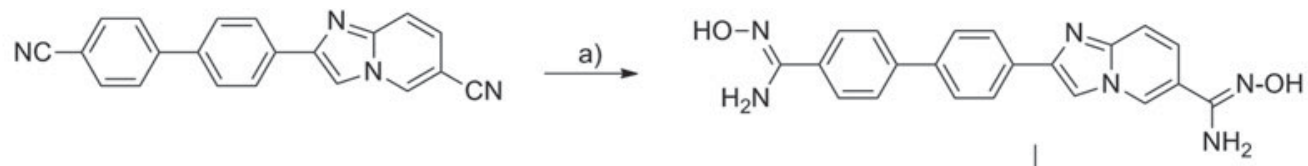<smiles>CC(=O)O/N=C(\N)c1ccc(-c2ccc(-c3cn4cc(/C(N)=N/OC(C)=O)ccc4n3)cc2)cc1</smiles>

Reagents and Conditions: a) $\mathrm{NH}_{2} \mathrm{OH}-\mathrm{HCl}, \mathrm{KO}-\mathrm{t}-\mathrm{Bu}, \mathrm{DMSO}$, rt b) $\mathrm{AcOH}, \mathrm{Ac}_{2} \mathrm{O}$, rt c) $\mathrm{H}_{2}, \mathrm{Pd}-\mathrm{C}, \mathrm{HOAc}$, rt

Scheme 2. Synthesis of an aromatic diamidine via a diamidoxime.

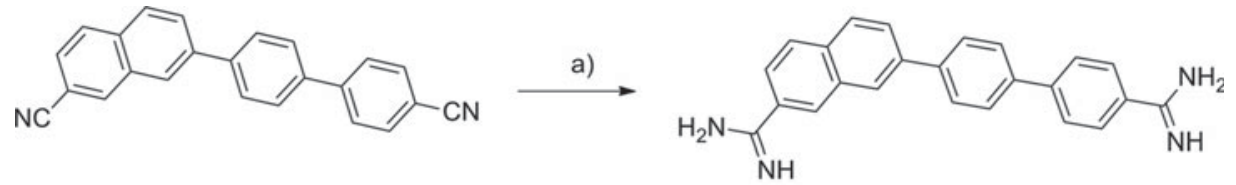

Reagents and Conditions: a)LiN(TMS) 2 , THF, rt overnight then $\mathrm{HCl}, \mathrm{EtOH}$ rt $12 \mathrm{~h}$

Scheme 3. Synthesis of an aromatic diamidine using $\mathrm{LiN}(\mathrm{TMS})_{2}$.

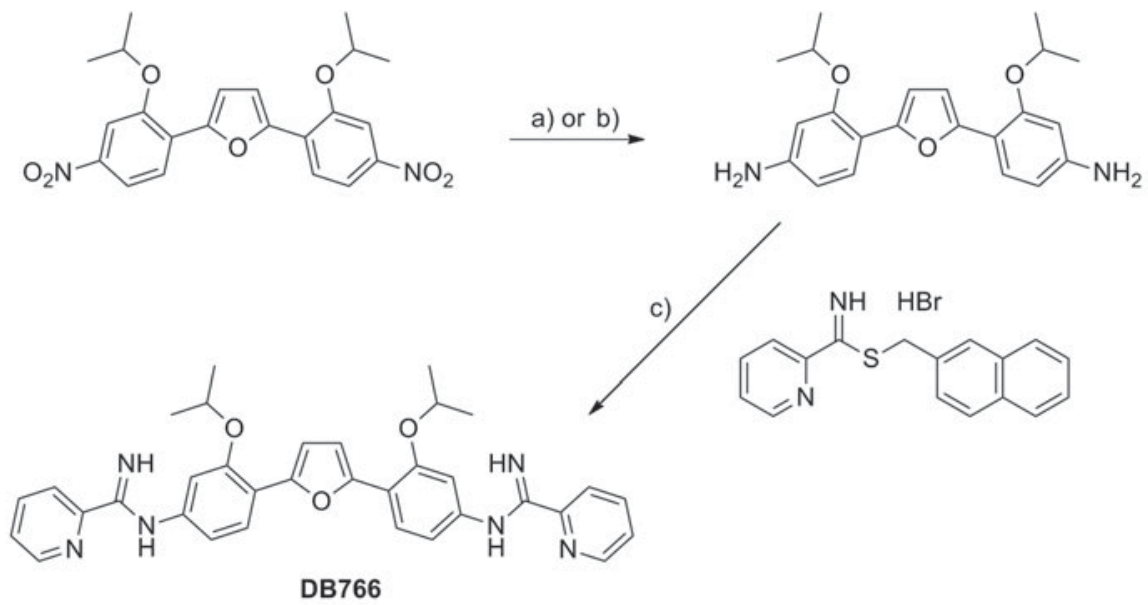

Reagents and Conditions: a) $\mathrm{H}_{2}, \mathrm{Pd} / \mathrm{C}, \mathrm{EtOAc}, \mathrm{EtOH}$, rt b) $\mathrm{SnCl}_{2}$ dihydrate, $\mathrm{EtOH}, \mathrm{DMSO}, 80^{\circ} \mathrm{C}$ c) $\mathrm{MeCN}, \mathrm{EtOH}$, rt

Scheme 4. Synthesis of the arylimidamide DB766. 
organisms, this amidine (Fig. 1) passed the plasma membrane as usual, but did not efficiently achieve access to the mitochondrion, thus not being able to destroy the kDNA. As no other significant biological target was detected in those parasites, these data indicated that the antiparasitic activity of amidines, like pentamidine requires their uptake and delivery to the mitochondrion, allowing binding to the $\mathrm{kDNA}$. As described above, considerable current literature data support kDNA as a primary antitrypanosomal biological target of these dications and there is also new evidence for their mechanism of action in T. brucei. Results from Englund's laboratory showed that blockage of kinetoplast replication through RNA interference of topoisomerase II production led to the death of bloodstream parasites (Wang and Englund, 2001). These findings clearly demonstrate that the kinetoplast is essential for these parasite forms. More recent research from the same group has definitively shown that in T. bruce $i$ compounds that act as $\mathrm{kDNA}$ binders destroy the kinetoplast structure and cause parasite death (Chowdhury et al. 2010). The same group reported in $T$. brucei that death triggered by ethidium bromide (EB - an intercalating agent also used as a fluorescent marker for DNA) was linked to its effect on parasite kDNA (Chowdhury et al. 2010). However, the existence of viable parasites lacking kDNA (dyskinetoplastic) has been a source of a longlasting controversy about the role of the kinetoplast as target and whether kDNA loss could be in fact the mechanism of killing. Additional studies indicated that $\mathrm{kDNA}$ is essential in bloodstream forms of $T$. brucei and that dyskinetoplastic parasites only survive due to a compensating mutation in the nuclear genome (Schnaufer et al. 2005; Lai et al. 2008). These important observations led the Englund group to re-study the question of $\mathrm{kDNA}$ as a drug target. They found that binding of EB to covalently closed kDNA minicircles released from the network during replication caused extensive DNA supertwisting, helix distortion, inhibition of replication, and resulted in $\mathrm{kDNA}$ loss, culminating in parasite death. Interestingly, although EB could also kill dyskinetoplastic trypanosomes by targeting nuclear DNA, death occurred at higher concentrations through inhibition of nuclear DNA replication. The effect on kDNA occurred at around a 10 -fold lower drug concentration as compared with the effect on the nuclear DNA, indicating the kinetoplast as the primary target but that the effect on nuclear replication can also contribute to cell killing (Chowdhury et al. 2010). While the studies performed by Englund's laboratory were performed with $\mathrm{EB}$, these data may contribute to the knowledge regarding the mechanism of action of other compounds that act in the kinetoplast structure. Evidence obtained by transmission electron microscopy showed that some aromatic dications also target the mitochondrial kinetoplast in Leishmania
(Hu et al. 2008) and T. cruzi (De Souza et al. 2006), demonstrating that kDNA targeting of these compounds holds for, at least, pathogenic kinetoplastids. Clearly, additional studies are needed to provide definitive proof regarding the mechanism of action of these dicationic compounds on different organisms.

It should be noted that binding to DNA may be only the initial step in the biological activity of most of these dications and other mechanisms are yet to be defined. It is likely that the functions of DNAtargeted control proteins or enzymes are directly or indirectly modified by dication binding to DNA for antiparasitic activity to occur. For this reason some optimum level of DNA binding is required, but a direct correlation of DNA binding constants and biological activity is not generally observed (Daliry et al. 2011). The experimental results obtained so far in trypanosomes and Leishmania led to a general concept that diamidines act on these parasites by targeting their kinetoplast (Hu et al. 2008; Wilson et al. 2008). The destruction of the kinetoplast by diamidines could occur, for example, by compound interference with topoisomerase IIcatalysed opening and rejoining of $\mathrm{kDNA}$ minicircles. In agreement with this model, Shapiro and Englund (1990) showed in a fundamental set of experiments that pentamidine, berenil and other antitrypanosomal drugs bind to DNA and selectively target kinetoplast topoisomerase II leading to its linearization. There are other DNA replication steps in the large, catenated kDNA network where drug binding could also cause replication errors and DNA degradation (Chowdhury et al. 2010). Additionally, the antiparasitic activity and relatively low host toxicity of dications suggest that the intricate structure of the catenated kDNA network must be also considered. Since there are thousands of DNA minicircles in the network, each with multiple closely spaced AT sequences, a very small compoundinduced error percentage in the normal biological functions of the kinetoplast could be enough to cause destruction of the network, kinetoplast disintegration and cell death. This structure is unique to kinetoplastid organisms and this fact may account for their generally low cytoxicity to mammalian cells. Minor topological effects of the compounds at the repeated AT sequences of the kDNA network could act in synergy, leading to a biologically catastrophic effect in the treated parasites.

It seems likely that mitochondrial functions in African trypanosomes are much more complex than previously realized. RNA editing, for example, a key kinetoplast function, has been demonstrated to be essential for survival of bloodstream forms of T. brucei (Schnaufer et al. 2001). Given the normal close coupling of kDNA, nuclear DNA and cell division; it is also possible that the loss of the kinetoplast disrupts normal cell division (Schnaufer et al. 2002). An interesting additional aspect of the 
alterations induced by diamidines on the kinetoplast topology and physiology is the occurrence of parasites expressing programmed cell death characteristics (Schnaufer et al. 2002; De Souza et al. 2006). Clearly, the kinetoplast is essential for trypanosomes and its destruction by diamidine treatment can yield the observed biological activity. In summary, 3 clear statements can be made with regard to the antiparasitic mechanisms of dicationic amidines. The kDNA (in kinetoplastid organisms) is a primary target of these dications which generally cause destruction of the kinetoplast. Nuclear DNA is a secondary target in these organisms while it is at least one of the main targets in other parasites such as Plasmodium (Purfield et al. 2009), although the evidence for this mode of action is less definitive. The nuclear mechanism is dominant in dyskinetoplastic organisms and this secondary mechanism accounts for the long held, but completely incorrect, view among some scientists that the kinetoplast could not be the primary target of any antiparasitic drug. Third, there are certainly other mechanisms of action of some compounds in this large and diverse group of molecules, but the evidence for any other specific mechanism is very limited and certainly not definitively established at present. An obvious corollary to these statements is that much more research on the antiparasitic mechanisms of this important set of compounds is urgently needed.

\section{PHARMACOKINETICS}

\section{Absorption}

As briefly presented above, the classical antiparasitic diamidines, e.g. pentamidine and furamidine (Fig. 1), are not well-absorbed through the gastrointestinal (GI) tract after oral administration, and hence are given by injection to achieve the desired bioavailability. The in vitro permeability of furamidine measured in Caco-2 cell monolayers was low, similar to that of the paracellular permeability marker mannitol, and it was modulated by the absence of $\mathrm{Ca}^{2+}$, suggesting a paracellular route for traversing epithelial membranes (Zhou et al. 2002). As stated in the section 'Design and synthesis', the high $\mathrm{p} K_{\mathrm{a}}$ values and the resulting positive charge at physiological pH preclude diamidine molecules from passively diffusing across lipid membranes, thus carrier-mediated transport is required to achieve cellular uptake. To overcome the absorption limitation of cationic diamidines, pro-drug strategies and novel structural designs have been employed to enhance oral absorption. The acid dissociation constant of the amidine group can be modulated by $N$-derivatization to form the amidoxime (e.g. DB290, DB821 and DB840) and alkyloxy prodrugs (e.g. pafuramidine, DB844 and DB868) (Fig. 3). The measured $\mathrm{p} K_{\mathrm{a}}$ values for DB290 and pafuramidine were $5 \cdot 2$ and $4 \cdot 1$, respectively, significantly lower than that of furamidine $\left(\mathrm{p} K_{\mathrm{a}}=11 \cdot 8\right)$. This lowered $\mathrm{p} K_{\mathrm{a}}$ resulted in an 85 -fold increase of the permeability of pafuramidine relative to furamidine (Zhou et al. 2002) although no increase was detected for DB290 due to extensive metabolism within the cells (Saulter, 2005). In addition to the pro-drug approach, amidine groups were modified to form AIAs by attaching the imino group of the amidine to an anilino nitrogen (e.g. DB745 and DB766; Figs 1 and 4$)$. This modification lowered the $\mathrm{p} K_{\mathrm{a}}$ to $7 \cdot 1$ and $7 \cdot 4$ for DB745 and DB766, respectively, and contributed to their oral activity against Leishmania and T. cruzi in mice and hamsters (Wang et al. 2010, Batista et al. 2010a,b; Zhu et al. 2012).

\section{Distribution}

Once absorbed, the cationic amidines as well as AIAs exhibit extensive distribution into various tissues. After a single oral dose $\left(10 \mathrm{mg} \mathrm{kg}^{-1}\right)$ of radio-isotope labelled pafuramidine to rats, concentrations of radioactivity in nearly all tissues exceeded those in blood (Midgley et al. 2007). Liver was the major organ of drug accumulation, where $13-21 \%$ of radioactivity was found 7 days post-dose and essentially all was in the form of the active compound furamidine. Other tissues, with significant concentrations of radioactivity included: kidney, adrenal, nasal mucosa, intestine and pancreas. Concentrations of radioactivity in the brain were similar to those in plasma, whereas they were below the limit of detection in the cerebrospinal fluid. The limited CNS exposure is consistent with the lack of cures for pafuramidine in the mouse and monkey models of second-stage HAT (Mdachi et al. 2009; Wenzler et al. 2009). More recently, novel aza-analogues of furamidine (DB820 and DB829, Fig. 3) and their methoxy pro-drugs (DB844 and DB868) (Fig. 3) have cured animals in the second-stage mouse $(100 \%)$ and monkey (43-100\%) models of HAT (Wenzler et al. 2009; Thuita et al. 2012; J. K. Thuita and R. Brun, personal communication), suggesting an improved brain penetration by the new aza-analogues. The AIA DB766 accumulated preferentially to the antileishmanial target organs (i.e. liver and spleen), as well as kidneys, with maximum concentrations up to 26-fold higher than those in plasma (Wang et al. 2010). The compound did not appear to get into the brain efficiently relative to the above tissues, with concentrations generally close to or below the corresponding plasma concentrations. Studies to delineate the mechanisms of the differential brain distribution of cationic diamidines are warranted and are currently underway.

\section{Metabolism}

Berger and coworkers demonstrated that pentamidine was extensively metabolized in the perfused rat 
livers with only $15 \%$ of recovered radioactivity as pentamidine after $4 \mathrm{~h}$ incubation (Berger et al. 1992). Two major metabolites were the alkyl linker oxidation products, accounting for approximately $62 \%$ of recovered radioactivity. Amidoxime formation through $N$-hydroxylation of pentamidine was a minor reaction pathway, accounting for $<1 \%$ of the recovered radioactivity. Unlike pentamidine, little metabolism has been observed for diamidines with a furan linker (e.g. furamidine, DB820 and DB829, Figs 1 and 3) replacing the alkyl chain in the pentamidine. As discussed in the section 'Design and synthesis', various pro-drugs of diamidines have been designed to improve oral bioavailability, by masking the positive charge of the amidine moiety using hydroxy, alkyloxy, acetoxy and amino acids (Clement and Raether, 1985; Boykin et al. 1996; Ismail et al. 2003; Kotthaus et al. 2011). Biotransformation of pafuramidine (Fig. 3), the methoxy pro-drug of furamidine, to the active furamidine is complex, involving multiple steps of sequential oxidative $O$-demethylation and reductive $N$-dehydroxylation reactions that are catalysed by cytochrome P450 enzymes and the cytochrome b5/NADH b5 reductase system, respectively (Saulter et al. 2005; Wang et al. 2006, 2007). Similar enzymatic reactions have been shown to be involved in the biotransformation of aza-analogues of pafuramidine (DB844 and DB868) to their respective active diamidines (DB820 and DB829) (Ansede et al. 2005; Generaux et al. 2013). Metabolism studies on AIAs are limited due to their early stage in drug development. Previous metabolic stability results using liver microsomes indicate that mice and hamsters metabolize AIAs more extensively than rats and humans (Wang et al. 2010). However, no information is available on the metabolite identity.

\section{Excretion}

Following oral administration in rats, pafuramidine was excreted predominantly in the feces (approximately $62 \%$ of dose) as the original pro-drug (20\% of dose), furamidine ( $22 \%$ of dose) and an intermediate mono-amidine metabolite (10\% of dose) (Midgley et al. 2007). Urinary excretion accounted for less than $5 \%$ of dose. A considerable portion of the dose $(6-21 \%)$ was retained in the body (mainly in the liver as furamidine) at 7 days post-dose and was slowly eliminated. Biliary excretion accounted for $14-26 \%$ of dose in the first $48 \mathrm{~h}$ post-dose. In general, methoxy pro-drugs of diamidines are eliminated rapidly (plasma $t_{1 / 2}$ ranging from 1 to $18 \mathrm{~h}$ in rats and monkeys), whereas the active diamidines exhibit extensive peripheral distribution (plasma $t_{1 / 2}$ ranging from days to weeks) and are often detectable in accumulating tissues (e.g. liver) several months postdose (Donnelly et al. 1988; Midgley et al. 2007; Thuita et al. 2012). Experimental excretion data for other diamidines/prodrugs and AIAs are scarce, but presumably follow a similar pattern.

As reviewed above, the most successes in improving dicationic amidines against trypanosomiasis infection like HAT are those that optimize pharmacokinetic properties in terms of oral bioavailability and/or target-tissue penetration, as pentamidine remains among the most active trypanocidal diamidines against HAT. Greater membrane permeability also contributed to the potent activity of AIAs against intracellular Leishmania and T. cruzi parasites. Future efforts should consider investigating mechanisms of tissue uptake of the diamidines to reduce unwanted high tissue accumulation, especially in the liver and kidney. The aza analogue DB829 represents such a new diamidine, which accumulated less in the rat liver and kidney (by approximately 2- and 5-fold, respectively), and yet showed twice more systemic exposure than furamidine following intravenous administration (Paine et al. 2010). DB868 (Fig. 3), the methoxy pro-drug of DB829, was also better tolerated in vervet monkeys than its predecessors and cured the monkeys in the acute and CNS model of HAT after oral administration (J. K. Thuita and R. Brun, personal communication).

EFFICACY AND SELECTIVITY OF AMIDINES AND THEIR DERIVATIVES AGAINST LEISHMANIA

Leishmania parasites cause a spectrum of disease ranging from cutaneous lesions to potentially fatal visceral infections of the mononuclear phagocyte system depending on the species of infecting organism. These parasites alternate between an elongated promastigote form that develops in the sandfly vector and a smaller, sessile amastigote form that exists within the macrophages of an infected host. Recent epidemiological studies estimate that between 0.7 and $1 \cdot 2$ million cases of cutaneous leishmaniasis occur annually, while anywhere from 0.2 to 0.4 million cases of visceral disease and between 20000 and 40000 deaths due to visceral leishmaniasis occur each year (Alvar et al. 2012). Chemotherapy for leishmaniasis has traditionally relied on the pentavalent antimonial drugs sodium stibogluconate and meglumine antimoniate; treatment for both visceral and cutaneous disease still depends on these injectable antimonials in most areas. However, resistance to pentavalent antimonials on the Indian subcontinent, a focal point for visceral leishmaniasis, has led to the increased use of the parenteral drugs amphotericin $\mathrm{B}$ and paromomycin as well as miltefosine, the first oral drug for the treatment of this disease (Picado et al. 2012). Unfortunately, all of these agents have one or more weaknesses, including adverse effects, high cost, the requirement of a long course of treatment, and fears due to favourable conditions for the development of drug-resistant parasites (Croft and Olliaro, 2011). A safe, effective and inexpensive 
oral treatment would be a welcome addition for the treatment of leishmaniasis, either as a component of combination therapy in areas where drug resistance has been reported or as a convenient form of monotherapy in regions where resistance has not been documented. Pentamidine (Fig. 1) was used in the past for the treatment of antimony-resistant visceral leishmaniasis infections, but response rates have decreased with time (Olliaro et al. 2005) as illustrated by a clinical study published in 2009 showing that pentamidine was inferior to amphotericin B in treating antimony-resistant visceral leishmaniasis in Bihar, India (Das et al. 2009). Pentamidine is currently the treatment of choice for cutaneous leishmaniasis caused by Leishmania guyanensis (van der Meide et al. 2009; Hu et al. 2012) and is also a recommended drug against Leishmania panamensis (World Health Organization, 2010) despite the fact that the clinical antileishmanial efficacy of pentamidine is relatively low. For example, while the administration of three $4 \mathrm{mg} \mathrm{kg}^{-1}$ doses of pentamidine by the intramuscular route was as effective as higher doses of meglumine antimoniate against cutaneous leishmaniasis caused by L. guyanensis, the cure rate after 6 months was only $58 \cdot 1 \%$ (Neves et al. 2011).

Pentamidine possesses good in vitro activity against extracellular Leishmania, but does not completely clear Leishmania-infected macrophages at concentrations that are not toxic to the host cell (Berman and Wyler, 1980; Gebre-Hiwot et al. 1992; $\mathrm{X}$. Zhu, unpublished observations). Many other diamidine-containing molecules also possess in vitro activity against Leishmania (Mayence et al. 2004; Huang et al. 2006; Bakunova et al. 2007, 2009, Bakunov et al. 2010), but the potency of these agents against intracellular Leishmania and their efficacy in animal models of leishmaniasis was not reported. Earlier papers indicated that diamidines possess limited activity in animal models of leishmaniasis (Hanson et al. 1977; Steck et al. 1981; Macharia et al. 2004), an observation that may also restrict the clinical utility of pentamidine and other diamidines for treating cutaneous and visceral leishmaniasis. The low in vivo efficacy of diamidines may be a result of the dicationic nature of these compounds precluding oral bioavailability and also limiting the passive diffusion of these molecules across membranes (see details in the sections 'Introduction' and 'Mechanisms of antiparasitic action'). This may be a major problem in the treatment of intracellular parasites such as Leishmania, where a drug is required to cross at least 3 sets of membranes (host cell membrane, parasitophorous vacuole membrane, parasite cell membrane) to enter the intracellular organism.

In 2003, Stephens et al. showed that AIAs possess potent activity against both extracellular and intracellular Leishmania donovani, with the potency being higher against intracellular organisms (Stephens et al. 2003). With their lower $\mathrm{p} K_{\mathrm{a}}$ values $(\sim 7)$ and greater lipophilicity compared with pentamidine (Wang et al. 2010), AIAs may exhibit superior activity against intracellular Leishmania due to improved membrane permeability. Several different structural variants of bis-AIAs (compounds containing 2 terminal amidine groups attached to a heterocycle) have now been prepared. The initial paper reporting the potent activity of AIAs against intracellular Leishmania described the synthesis and evaluation of a series of 8 symmetrical bis-AIAs containing different functional groups on the phenyl rings of the diphenylfuran linker. The potency of these compounds against intracellular L. donovani ranged from 150-3600 nu (Stephens et al. 2003). A broader series of over 50 symmetrical bis-AIAs was reported by Collar et al. in 2011; these compounds were tested for their ability to reduce intracellular Leishmania amazonensis parasite burdens. Compounds with 2-pyridyl terminal groups and fairly large hydrophobic substitutions on the diphenylfuran linker showed potent activity. However, when the substitutions became too large (i.e. benzyloxy or isobutoxy), potency was diminished. In terms of the terminal groups, the 2-pyridyl terminal substitution was superior to other heterocyclic substitutions such as 2-pyrimidyl, 2-pyrazinyl and 2-pyrrolyl, although a compound with a 2-methyl-5-thiazolyl terminal group retained potent intracellular activity (Collar et al. 2011). Symmetrical bis-AIAs containing different linker groups have also been synthesized and evaluated against intracellular Leishmania. Compounds with 1,4-phenyl and 1,4-phenylenediamine linkers showed dramatically reduced antileishmanial potency, while compounds with 4,4'-biphenyl, 4,4'-oxydianiline and 4,4'-oxybis (methylene)dianiline linkers retained antiparasitic activity (Banerjee et al. 2012). Bis-AIAs containing unsymmetrical substitutions on the diphenylfuran linker also retain potent activity against intracellular Leishmania; an AIA bearing an isopropoxy substitution on one of the 2 phenyl rings of the diphenylfuran linker displayed an $\mathrm{IC}_{50}$ value of $5 \cdot 3 \mathrm{nM}$ against $L$. donovani and $93 \mathrm{nM}$ against L. amazonensis (Reid et al. 2012). A structure-activity map summarizing the in vitro antileishmanial potency of bis-AIAs was recently published (Reid et al. 2012) and examples of active and inactive bis-AIAs against intracellular Leishmania are given in Fig. 4. The most promising AIAs in terms of their in vivo antileishmanial potential are 2,5-bis[2-(2-propoxy)4-(2-pyridylimino)aminophenyl]furan and the closely related 2,5-bis[2-(2-cyclopentyloxy)-4-(2pyridylimino)aminophenyl]furan. When prepared as its dihydrochloride salt form, the 2-propoxy compound is known as DB766, while as its dimesylate, it is termed DB1960. The cyclopentyloxy compound dihydrochloride salt has the code name 
DB1852, while the corresponding dimesylate is DB1955 (Figs 1 and 4). DB766 displayed IC $_{50}$ values of 36, 87 and $14 \mathrm{~nm}$ against intracellular L. donovani, L. amazonensis and Leishmania major amastigotes, respectively, comparable to the in vitro potency of the clinically applied antileishmanial drug amphotericin B. When tested orally in animal models of visceral leishmaniasis, DB766 reduced L. donovani parasite burdens in the liver by $71 \%$ and $89 \%$ when administered to infected $\mathrm{BALB} / \mathrm{c}$ mice and golden hamsters at $100 \mathrm{mg} \mathrm{kg}^{-1} \mathrm{day}^{-1} \times 5$; the compound was not mutagenic in the Ames test (Wang et al. 2010). DB1852 was less active than DB766 against intracellular Leishmania in vitro, but showed in vivo potency similar to that of DB766 in the murine visceral leishmaniasis model. The corresponding mesylate salts of DB766 and DB1852, DB1960 and DB1955, respectively, were $5 \cdot 3$-fold and $3 \cdot 1$-fold more soluble than their hydrochloride salt counterparts, allowing for repeat-dose toxicology studies to be performed at doses up to $500 \mathrm{mg} \mathrm{kg}^{-1}$ day $^{-1}$. The maximum tolerated dose of both mesylate salts was found to be $<100 \mathrm{mg} \mathrm{kg}^{-1} \mathrm{day}^{-1}$ by the oral route, with liver, kidney and haematological toxicity observed at high doses and microscopic findings in the GI tract observed at lower doses. DB1960 was more toxic than DB1955, but neither compound exhibited a sufficient therapeutic window to move forward with pre-clinical development (Zhu et al. 2012). Unfortunately, other bis-AIAs that display potent in vitro antileishmanial activity are more toxic than DB766, DB1955 and DB1960 in vivo (Banerjee et al. 2012; Reid et al. 2012 and X. Zhu, unpublished observations). Bis-AIAs are extremely potent against intracellular L. donovani $\left(\mathrm{IC}_{50}\right.$ values in the mid to low nanomolar range), but toxicity issues have precluded the further development of the class as candidates against visceral leishmaniasis. Since the mechanism of action of the AIAs is unknown, better understanding of the target(s) of the AIAs could lead to the design of more selective agents with a greater therapeutic window. While diamidines cause dilation of the Leishmania mitochondrion (Croft and Brazil, 1982; Hu et al. 2008), ultrastructural investigation of the effects of DB766 in L. donovani axenic amastigotes reveals little effect on this parasite organelle (T. Pandharkar, unpublished observations). The results of further mechanistic investigations with AIAs will hopefully benefit future antileishmanial drug discovery efforts.

EFFICACY AND SELECTIVITY OF AMIDINES AND THEIR DERIVATIVES AGAINST T. CRUZI

The obligatory intracellular protozoan, T. cruzi is the aetiological agent of Chagas disease, an important and neglected tropical disease, which affects more than 10 million people in endemic areas of Latin America (Dias, 2009). Chagas disease has
2 phases: the acute, which appears shortly after the infection, and the chronic phase that develops in about $20-30 \%$ of the infected individuals, after a silent period of years or decades, called the indeterminate phase (Rocha et al. 2007). In both clinical stages, tissue damage is directly induced by the parasite, or indirectly, by parasite-driven immune modulation (Coura and Borges-Pereira, 2012). The main clinical manifestations of Chagas disease are cardiac and/or digestive alterations but the mechanisms that govern this pathogenesis are not fully understood (Marin-Neto and Rassi, 2009). Due to the well-known undesirable side effects, and the occurrence of parasite strains naturally resistant to both nitro-heterocyclic compounds (Benznidazole and Nifurtimox) associated with their poor efficacy in the later chronic disease stage, the identification of novel anti-T. cruzi agents are justified (Romanha et al. 2010). However, as a consequence of the low interest of most pharmaceutical companies and the lack of standardized/proper experimental protocols and animal models for drug screening, very few compounds moved to clinical trials, including 2 triazole inhibitors of the parasite's C14 $\alpha$ sterol demethylase: posaconazole (Schering-Plough Research Institute) and a pro-drug of ravuconazole (E1224 (Eisai Company)) (De Castro et al. 2011). However, these azoles have important limitations mainly related to their high costs and the potential to induce parasite resistance as they enhance $T$. cruzi sterol 14alpha-demethylase gene expression and require increasing doses to maintain constant cellular growth inhibition (Lepesheva and Waterman, 2011). Thus, the identification of other promising trypanocidal candidates is urgently needed. In recent years, a considerable amount of data has been collected regarding the effect of amidine-containing molecules against T. cruzi (Soeiro and De Castro, 2011). While pentamidine does not display potent activity $(>32 \mu \mathrm{M})$ on bloodstream trypomastigotes of T. cruzi (Zhu et al. 2012), other aromatic diamidines show considerable in vitro effects (De Souza et al. 2004, Pacheco et al. 2009; Batista et al. 2010a; Daliry et al. 2011; Da Silva et al. 2011a). For instance, 3-bromo4-methyl-2,5-bis(4-amidinophenyl)thiophene (DB1362 - see Fig. 5) induced a dose-dependent trypanocidal activity giving an $\mathrm{IC}_{50}$ value of $6 \mu \mathrm{M}$, and provided a partial reduction of the parasitaemia levels in an experimental mouse model of acute infection using the Y strain of T. cruzi (Da Silva et al. 2008). DB569, an $N$-phenyl derivative of furamidine (DB75), exhibited a dose- and time-dependent activity towards both bloodstream $\left(\mathrm{IC}_{50}=2 \mu \mathrm{M}\right)$ and amastigotes $(>4 \mu \mathrm{M})$ of different T. cruzi strains (De Souza et al. 2004). In vivo, DB569 significantly reduced the cardiac parasite burden in mice, partially increased survival rates, and lowered the levels of alanine aminotransferase and creatinine, indicating a protective role against renal and hepatic lesions 
induced by infection (De Souza et al. 2007). DB569 also protected infected mice from electric cardiac alterations due to T. cruzi invasion possibly due to the reduced parasitism associated with the modulation of an aggressive host immune response, since this amidine (but not benznidazole) decreased CD8 + $T$ cells levels at the inflamed hearts of the infected and treated mice (De Souza et al. 2007). Interestingly, diamidines like DB569 control intracellular parasitism more efficiently when professional phagocyte cells such as macrophages are used as host cells as compared with non-professional phagocytes such as cardiac cells (De Souza et al. 2004). These results suggest that depending on the host cell type, different levels of trypanocidal events may be triggered directly by these aromatic compounds in mammalian cells, contributing to the control of parasite proliferation. In fact, E. M. De Souza and M. N. C. Soeiro (unpublished data) demonstrate the ability of amidines like DB569 to induce nitric oxide production by mammalian cells giving strong support that not only the antiparasitic mechanism of action of these compounds should be more thoroughly investigated but also, most importantly, their potential effect on host cells metabolism and activation of trypanocidal responses that could also limit the parasite burden.

As described for Leishmania, AIAs (especially bisAIAs - see the section 'Efficacy and selectivity of amidines and their derivatives against Leishmania') are highly potent against $T$. cruzi, with many of them displaying superior efficacy as compared with classical aromatic diamidines (e.g. DB75 and pentamidine) (De Souza et al. 2004; Da Silva et al. 2007; Pacheco et al. 2009). Studies with bloodstream forms demonstrated that the AIA DB766 $\left(\mathrm{IC}_{50}=60 \mathrm{nM}\right.$, Batista et al. 2010a) is about 260-fold more potent than DB75 $\left(\mathrm{IC}_{50}=16000 \mathrm{~nm}\right.$, De Souza et al. 2007), showing that minor modifications of the chemical structure of amidine-containing molecules can result in higher selectivity and efficacy. As also discussed for Leishmania in the section 'Efficacy and selectivity of amidines and their derivatives against Leishmania' of the present review, the superior activity of AIAs compared with amidine compounds may be related to their lower $\mathrm{p} K_{\mathrm{a}}$ values and greater lipophilic character, contributing to their efficient entrance into host and parasite cell membranes. In fact, despite the fact that T. cruzi disrupts the parasitophorous vacuole membrane and proliferates freely within the cytoplasm of the host cells, in order to be active against this protozoan infection, especially during the late chronic phase, a desirable drug candidate must cross both $T$. cruzi and host plasmalemmas to reach the parasite intracellular milieu and act on its cellular targets. DB766 exhibited strong activity (in the nanomolar range) and excellent selectivity on intracellular amastigotes, showing striking effects upon a large panel of $T$. cruzi strains including parasite isolates that circulate in peridomiciliar and sylvatic ecotopes from different regions from Brazil (Ceará State and Amazon region), and those that are naturally resistant to benznidazole and nifurtimox (e.g. Colombiana and $\mathrm{YuYu}$ ), with higher efficacy in vitro than the reference drugs (Batista et al. 2010a). DB766 as well as several other AIAs (such as DB745, DB1831 and DB1868 - Figs 4 and 5) keep a high activity at $4{ }^{\circ} \mathrm{C}$ in the presence of $96 \%$ mouse blood, being at least $30 \cdot 6$-fold more effective than gentian violet, the reference drug for blood therapy in Chagas disease (Batista et al. 2010a, 2011; Da Silva et al. 2012). These results demonstrate the potential application of AIAs in the prophylaxis of T. cruzi infection acquired through contaminated blood stored in blood banks. On the other hand, other AIAs (like DB1852 - Fig. 5) showed decreased activity when incubated at $4{ }^{\circ} \mathrm{C}$ even in the absence of blood, suggesting that such a decrease may be related to impairment of drug uptake due to a transportmediated mechanism and/or to decreased cellular target metabolism (Da Silva et al. 2011a, b).

Due to the high efficacy and selectivity of novel bisAIAs, some compounds such as DB766 (selectivity index (SI) >533) were assessed with in vivo models (Batista et al. 2010a). DB766 suppressed the parasite load in the blood and cardiac tissues (80->99\% reduction), presented similar efficacy as benznidazole in mouse models of T. cruzi-infection employing $\mathrm{Y}$ (moderated resistant) and Colombiana (high resistant) strains, using oral and intraperitoneal (i.p.) doses up to $100 \mathrm{mg} \mathrm{kg}^{-1}$ day $^{-1}$ (given after the establishment of parasite infection), and provided $90-100 \%$ protection against mortality (Batista et al. 2010a). The effectiveness of this AIA in eradicating intracellular parasites (as we observed in cardiac cells during in vitro and in vivo infection, Batista et al. 2010a) may be related to its pharmacokinetic properties (see section on 'Pharmacokinetics') including long half-lives and large volumes of distribution (Wang et al. 2010). This issue is highly relevant, since the poor activity of benznidazole during the chronic stages of CD has been attributed, at least in part, to its poor pharmacokinetic properties, such a relatively short half-life and limited tissue penetration (Soeiro and De Castro, 2009). Although it is not a pro-drug, DB766 showed good activity upon oral administration (dose $100 \mathrm{mg} \mathrm{kg}^{-1}$ day $^{-1}$ ) (Batista et al. 2010a). However, using a similar mouse model of acute T. cruzi infection (Y strain), the mesylate salt of DB766 (DB1960) only decreased the parasitaemia levels by $46 \%$ when given orally at $100 \mathrm{mg} \mathrm{kg}^{-1}$ day $^{-1} \times 5$ (Zhu et al. 2012). It is possible that the increased solubility of DB1960 may result in decreased permeability and therefore lesser drug accumulation in parasitized organs, resulting in lower efficacy (Zhu et al. 2012).

Another highly effective AIA that has been screened against T. cruzi and showed high activity is DB1852, exhibiting $\mathrm{IC}_{50}$ values of $60 \mathrm{~nm}$ against 
bloodstream trypomastigotes (Y strain) (Da Silva et al. 2011b). When assayed in vivo, the mesylate salt of DB1852 (DB1955) had no effect on parasitaemia when administered using the same dosing regimen as DB1960 and DB766 in a similar mouse model of acute infection (Y strain). The lower in vivo efficacy of DB1960 and DB1955 may be due to their lower accumulation in the heart and plasma of infected mice, which are important sites of T. cruzi infection (Zhu et al. 2012). Additionally, another point of discussion is the fact that DB766, DB1955 and DB1852 displayed similar effects upon bloodstream forms (60-70 nM), but the former AIA was much more potent against intracellular forms $\left(\mathrm{IC}_{50}=25\right.$, 180 and $538 \mathrm{nM}$ for DB 766, DB 1955 and DB1852, respectively). Although a direct correlation between in vitro and in vivo is not always found, cumulative data suggest that the activity against intracellular amastigotes, which are the reproductive forms in the vertebrate host, represents a more reliable determinant in the selection of effective compounds to move from in vitro to in vivo assays (De Castro et al. 2011). The excellent activity of DB766 motivated the design and synthesis of novel structurally related compounds like the AIA - DB1831 (hydrochloride salt) and its mesylate salt form (DB1965) (Da Silva et al. 2012). DB1831 displayed excellent activity against bloodstream trypomastigotes $\left(\mathrm{IC}_{50}=20 \mathrm{nM}\right)$, and, as did DB766, retained excellent efficacy at $4{ }^{\circ} \mathrm{C}\left(\mathrm{IC}_{50}\right.$ values of 80 and $24 \mathrm{~nm}$ with or without mouse blood, respectively). When assessed against intracellular amastigotes grown in cardiac cell cultures, DB1831 exhibited an outstanding $\mathrm{IC}_{50}$ of $5 \mathrm{~nm}$ already at $48 \mathrm{~h}$ after the initiation of treatment, as well as very high SI values (2900). Due to its poor solubility, a methanesulfonic acid salt (DB1965) was obtained for further in vivo analysis. DB1965 administered i.p. for 5 daily consecutive doses (starting at the onset of parasitaemia) reduced parasitaemia levels by 93 and $99 \%$ when administered at doses of 12.5 and $25 \mathrm{mg}$ $\mathrm{kg}^{-1}$, respectively, similar to the reference drug (Da Silva et al. 2012). Although treatment with $12.5 \mathrm{mg} \mathrm{kg}^{-1}$ of DB1965 for 10 days suppressed the parasitaemia and gave $90 \%$ protection against mortality, longer periods of therapy were not performed due to undesirable side effects (like hyperactivity) and a combined treatment of $5 \mathrm{mg} \mathrm{kg}^{-1}$ DB1965 +50 mg kg-1 benznidazole (suboptimal dose) was chosen following the same protocol previously carried out with DB766, under a scheme of 20 daily consecutive doses (Batista et al. 2011). However, despite the promising trypanocidal effects of AIAs in combination with benznidazole, neither DB766, DB1965 nor the reference drug induced parasitological cure (Batista et al. 2011b; Da Silva et al. 2012), possibly due to the highly stringent protocol employed (male mice, only 20 days of compound administration, starting treatment at the onset of parasitaemia, using only positive infected animals). In fact, previous studies performed in $T$. cruzi-infected mouse models reporting high parasitological cure rates (e.g. benznidazole) employed different protocols using female mice (instead of male mice as used for AIAs), longer periods of treatment $(\geqslant 40$ days) or abortive scheme (starting therapy $24 \mathrm{~h}$ after parasite inoculation) (Urbina et al. 1998; Molina et al. 2000; Bustamante et al. 2008). Although displaying quite similar results as benznidazole, DB1 965 was not as active in vivo as DB766, especially by p.o. administration and was also less well tolerated according to acute toxicity studies (Da Silva et al. 2012). Since the only difference in structure between DB766 and DB1831 concerns the terminal groups (pyridine and pyrimidine, respectively), differences in toxicity and efficacy between DB766 and DB1965 may also be attributed to this minor modification. Thus, further investigations are required to sort out this effect, allowing the design of novel AIAs bearing pyrimidine and pyridine units since they seem to be advantageous for retaining activity against $T$. cruzi. When other T. cruzi candidates that have moved (e.g. ravuconazole with $\mathrm{IC}_{50}=1 \mathrm{~nm}$, Urbina et al. 2003) or are expected to move soon to clinical trials (protease inhibitors such as K11777 - McKerrow et al. 2009) are compared with DB $766\left(\mathrm{IC}_{50}=25 \mathrm{nM}\right)$, similar efficacy is found against intracellular amastigotes, meriting further investigation on AIAs against parasitic infection on intracellular microorganisms. In fact, the biological activity of 7 novel AIAs was recently assayed for 48 and $24 \mathrm{~h}$ against intracellular parasites and bloodstream forms (Y strain), respectively. The data demonstrated the outstanding trypanocidal effect of AIAs against T. cruzi, especially DB1853, DB1862, DB1867 and DB1868 (Fig. 6), giving $\mathrm{IC}_{50}$ values ranging between 16 and $70 \mathrm{nM}$ against both parasite forms. All AIAs presented superior potency and some, such as DB1868, also exhibited promising activity as candidates for blood prophylaxis (Da Silva et al. 2011a, b). The lower activity of DB1850 may be due to the markedly different terminal groups (5-membered ring thiazoles for DB1850 and 6-membered ring pyridine or pyrimidine for the others). Also, in this study, the higher activity against $\mathrm{BT}$ forms suggests that a range of variations in the $\mathrm{O}$-alkyl groups $\left(\mathrm{OCH}_{2} \mathrm{CF}_{3}\right.$ to $O$-c-pentyl) is tolerated but additional experimental assays are needed to further evaluate this hypothesis.

Another interesting point is that some of these AIAs, such as DB745, can be considered fast-acting compounds. Time-point studies using $10 \mu \mathrm{g} \mathrm{mL}^{-1}$ of each compound demonstrated that after $5 \mathrm{~min}$ of incubation, DB745 induced $51 \%$ of trypomastigote lysis whereas the diamidine DB569 and the AIA DB766 displayed only 16 and $27 \%$ of parasite death, respectively (Da Silva et al. 2011a). However, longer periods of incubation $(60 \mathrm{~min})$ resulted in a similar trypanocidal effect for both AIAs (>96\%), while DB569 resulted in about $50 \%$ of parasite lysis 
(Da Silva et al. 2011a). The rapid toxicity of DB745 represents a desirable property for treating acute parasitic infections such as in Chagas disease, and further studies should be carried out to explore the possibility whether different transport mechanisms and/or cellular targets may be operating. Importantly, the different efficacies of some bisAIAs (like DB1852 and DB1890) against infective and non-proliferative bloodstream forms compared with infective and highly multiplicative (intracellular) stages may be due to differences in uptake, mechanisms of action and/or different targets among these different parasite forms (Da Silva et al. 2011ab47). In fact, striking differences have been found when the uptake of classical diamidines (like DB75) and AIAs (like DB766) has been evaluated on epimastigotes (non-infective but highly proliferative forms found in blood-sucking vectors) and bloodstream trypomastigotes: while DB75 (but not AIAs like DB766) is internalized by trypomastigotes via adenosine/adenine transporter systems, this is not observed in epimastigotes (E. Goulart and M. N. C. Soeiro, unpublished data). These data demonstrated that differences in sensitivity of dicationic compounds among the distinct T. cruzi forms may be due to (i) different transporters of diamidines and AIAs according to parasite evolutive stage and/or (ii) different cellular targets may be operating, and these must be further explored.

In summary, the excellent antitrypanosomal efficacy of these novel bis-AIAs against T. cruzi stimulates further in vivo studies and justifies the screening of new analogues with the goal of establishing a useful alternative therapy for Chagas disease.

\section{EFFICACY AND SELECTIVITY OF AMIDINES AND THEIR DERIVATIVES AGAINST APICOMPLEXAN PARASITES}

Apicomplexan parasites cause a wide range of highly relevant diseases in humans such as malaria, babesiosis, cryptosporidiosis and toxoplasmosis. Cryptosporidiosis, babesiosis and toxoplasmosis also have a high impact on animal health and are zoonotic diseases. Neosporosis (caused by Neospora caninum) and besnoitiosis (caused by Besnoitia besnoiti) are responsible for high economic losses in farm animal production worldwide (Müller and Hemphill, 2013). The efficacies and interactions of amidine compounds with apicomplexans have been investigated in vitro and, to some extent, also in vivo.

\section{Vector-borne apicomplexans: Plasmodium and Babesia}

The genus Plasmodium causes malaria, and thus represents a major burden in tropical and subtropical countries with over 1 million deaths annually.
The clinically most important agent is Plasmodium falciparum, responsible for malaria tropica, the most severe form of the disease. While a number of chemotherapeutically active antimalaria compounds have been developed and applied in the field, resistance has been spreading rapidly, and activity against drug-resistant isolates is a prerequisite for any lead compound to be developed (Mäser et al. 2012). In addition, other requirements include excellent oral bioavailability, low production costs, activity against all human-pathogenic Plasmodium species, and ideally cure by a single dose. Pentamidine-analogues demonstrated antimalarial potency (Bell et al. 1990; Stead et al. 2001; Bray et al. 2003), but with a low bioavailability since, as previously described, the capacity to pass through cellular membranes is hampered due to ionization of the 2 cationic moieties at physiological pH. Bakunova et al. (2007) synthesized 43 bisbenzofurans, of which 22 were more active against $P$. falciparum than pentamidine, and 7 dications were more effective than artemisinin. A series of pentamidine congeners bearing the benzofuran motif were synthesized and 7 compounds exhibited in vitro activities against $P$. falciparum that were superior to pentamidine (Bakunova et al. 2009). More recently, novel dicationic triazoles were shown to exhibit promising activities against a chloroquine-resistant $P$. falciparum in vitro, with $\mathrm{IC}_{50}$ s ranging from $0 \cdot 6 \mathrm{nM}$ to $8 \cdot 39 \mu \mathrm{M}$ (Bakunov et al. 2010). Eight of these analogues displayed better antiplasmodial activities in vitro than pentamidine $\left(\mathrm{IC}_{50}=58 \mathrm{nM}\right)$, and 4,4'-disubstituted diimidazoline was the most potent one, with an $\mathrm{IC}_{50}$ of $0.6 \mathrm{~nm}$ and an SI of $>316667$ as determined by in vitro exposure of L6 rat myoblast cells. In comparison, the most effective antimalarial drug artemisinin exhibits an $\mathrm{IC}_{50}$ of $6 \mathrm{~nm}$ and a SI of 75000 (Bakunov et al. 2010).

The genus Babesia comprised approximately 100 described species. Babesiosis has gained increased interest as a zoonotic disease that is transmitted by ticks, and affects a wide range of domestic and wild animals. The major economic impact is on the cattle industry, but infections also occur in horses, sheep, goats, pigs and dogs (Müller and Hemphill, 2013). Babesia bovis and Babesia bigemina are widespread species affecting cattle in tropical and subtropical areas, while Babesia divergens infects cattle in Europe (de Waal and Combrink, 2006). In ticks, the blood stages of the parasite are ingested during a bloodmeal and undergo development. Subsequent transmission of Babesia sporozoites to the host occurs when infected larvae, nymphs and/or adults feed on their hosts. Babesia parasites invade and proliferate within erythrocytes but, in contrast to Plasmodium spp., they do not develop in a parasitophorous vacuole; they divide by binary fission (not by schizogeny) and do not form hemozoin. In Europe, human cases of babesiosis are mostly caused by $B$. divergens, while in North America most human cases involve the rodent 
species Babesia microti (Kjemtrup and Conrad, 2000). Sporadic cases of human babesiosis have also been identified in Asia, Africa and South America. The standard drugs used against babesiosis in animals are atovaquone, imidocarb dipropionate and diminazene aceturate, of which only imidocarb acts consistently parasiticidal. In humans, Babesia infections are treated with combinations of quinine/ clindamycin or atovaquone/azithromycin (Vial and Gorenflot, 2006). A recent study on the in vitro activities of novel diamidine compounds against 2 $B$. divergens strains showed that the most potent compound, a diphenyl furan, had an outstandingly low $\mathrm{IC}_{50}$ of $1.5 \mathrm{ng} \mathrm{mL}^{-1}$ (Nehrbass-Stüdli et al. 2011). Several test compounds, including terphenyls, benzimidazoles, diphenyl furans, pentamidine and pentamidine analogues, were effective against $B$. microti in mice at a dosage of $12 \cdot 5$ and/or $25 \mathrm{mg} \mathrm{kg}^{-1}$ of body weight given by the subcutaneous route for 4 days.

\section{Cryptosporidium}

Cryptosporidiosis is a cause of diarrheal illness in immunocompetent hosts such as travellers and infants attending day care, and represents an important opportunistic diarrheal disease in immunecompromised humans. Cryptosporidiosis occurs worldwide, and also affects many young farm mammals as well as cats and dogs, some times with fatal outcomes. The only drug currently licensed for the treatment of Cryptosporidium parvum infection in humans is the nitro-thiazole nitazoxanide, but this compound is ineffective in immune-compromised patients (Hemphill et al. 2006), and its use in neonatal calves has been shown to be accompanied with severe adverse effects (Schnyder et al. 2009). Compounds such as halofuginone and decoquinate are reported to exhibit promising effects and the antibiotic paromomycin is frequently used (Lefay et al. 2001; Lallemand et al. 2006), but results are variable and none of these drugs are licensed for the treatment of cryptosporidiosis, neither in humans nor in food animals. Pentamidine analogues and aryl furans were investigated in vitro and in vivo employing C. parvum-infected Hsd/ICR suckling mice (Blagburn et al. 1991, 1998a), demonstrating that oral application of a diaryl furan by gavage at a dosage of 17.0 and $8.5 \mathrm{mg} \mathrm{kg}^{-1}$ for 5 days resulted in a reduction in oocyst shedding to $5 \cdot 1 \%$ and $6 \cdot 4 \%$ of levels, respectively, as compared with non-treated controls. In a subsequent study (Blagburn et al. 1998b), application of 2,7-diamidinocarbazole dihydrochloride at dosages of 10 and $19 \mathrm{mg} \mathrm{kg}^{-1}$ resulted in oocyst outputs of only $0 \cdot 3$ and $0 \cdot 8 \%$ respectively. In comparison, nitazoxanide applied orally at 100 $\mathrm{mg} \mathrm{kg}^{-1}$ yielded a reduced oocyst output of $26 \%$, and at $150 \mathrm{mg} \mathrm{kg}^{-1}$ the residual oocyst output was $4 \cdot 3 \%$ compared with untreated neonatal mice (Blagburn et al. 1998b). Paromomycin on the other hand, applied at $50 \mathrm{mg} \mathrm{kg}^{-1}$ exhibited a reduction of oocyst shedding to $1 \cdot 2 \%$ compared with untreated control mice. In these experiments, drugs were applied already $4 \mathrm{~h}$ after infection, meaning that parasites did not establish substantial numbers of developmental stages prior to exposure to the compounds.

\section{Cyst-forming apicomplexans: Toxoplasma gondii,} $\mathrm{N}$. caninum and $\mathrm{B}$. besnoiti

Toxoplasma gondii is the most successful of all apicomplexan parasites, infecting approximately $30-50 \%$ of the human population, and is highly prevalent in all warm-blooded animals, including birds. In an immunocompetent host, infection is normally benign and asymptomatic (Barratt et al. 2010). Clinical problems can arise in individuals with an immature immune system or in immunecompromised individuals (e.g. AIDS patients), where infection can lead to toxoplasmic encephalitis or even death. Toxoplasmic encephalitis occurs as a result of the reactivation of brain cysts that encapsulate slowly proliferating bradyzoites, which then undergo bradyzoite-to-tachyzoite stage conversion (Henriquez et al. 2010). Secondly, congenital toxoplasmosis poses a major health risk upon primary maternal infection during pregnancy, leading to placental or fetal infection and abortion or damage of the fetus (Feldman et al. 2010). In addition, $T$. gondii is also a highly significant economic and veterinary medical concern in the livestock industry (Dubey, 2009). The chemotherapeutic options for the treatment of toxoplasmosis are limited. Synergistic combination therapies comprised of sulfadiazine/ pyrimethamine, targeting the synthesis and the reduction of folic acid in tachyzoites, or clindamycin/pyrimethamine, are the most efficient options, but are prone to adverse effects, and the noneffectiveness of compounds against bradyzoites that are enclosed in tissue cysts represents a major problem (Barratt et al. 2010). The in vitro efficacy of pentamidine and some pentamidine analogues against $T$. gondii has been investigated earlier (Lindsay et al. 1991) and proliferation-inhibitory properties were reported at concentrations of around $10 \mu \mathrm{g} \mathrm{ml} \mathrm{m}^{-1}$. Leepin et al. (2008) screened 19 dicationic compounds and demonstrated the in vitro efficacy of 4 derivatives of DB75 (furamidine), which are built symmetrically with the 2 core structurebenzene rings being altered. In the diamidine DB811, this occurs through the addition of 2 chloro atoms. In the AIA DB750, two hydroxy groups are added, and in the AIAs DB766 and DB786 isopropoxy groups are added at different positions. These compounds exhibited $\mathrm{IC}_{50}$ s between $0 \cdot 16$ and $0 \cdot 66 \mu \mathrm{M}\left(0 \cdot 14-0 \cdot 5 \mu \mathrm{g} \mathrm{ml}^{-1}\right)$. Neither pentamidine nor furamidine exhibited meaningful in vitro activity against $T$. gondii. Transmission electron microscopy 
demonstrated clear structural damage within drugtreated parasites, while host cells remained unaffected. However, since neither of these compounds exhibited detectable fluorescent properties, it was not possible to study in which cellular compartments these compounds localized (Leepin et al. 2008). More recently, Kropf et al. (2012) re-investigated the in vitro characteristics of the most promising compound, DB750, in the virulent $T$. gondii $\mathrm{RH}$ strain (genotype 1) and an avirulent strain, Me49 (genotype 2). Three-day-growth assays showed that DB750 inhibited the proliferation of tachyzoites of both strains with an $\mathrm{IC}_{50}$ of $0 \cdot 11$ and $0 \cdot 13 \mu \mathrm{M}$, respectively, but the drug did not affect extracellular parasites. Thus no inhibition of host cell invasion upon DB750 treatment was observed. In addition, fibroblast monolayers that were treated with $1 \mu \mathrm{M}$ DB750 for $12 \mathrm{~h}$ prior to infection were subsequently infected, and further culture of these infected fibroblasts in the absence of the DB750 for 3 days resulted in a pronounced inhibition of parasite proliferation, indicating that DB750 was actively taken up and accumulated within the host cells, causing a memory effect. However, upon continuous exposure to DB750 for 5-6 days, T. gondii tachyzoites adapted to the drug and resumed proliferation in the presence of a DB750 concentration of up to $1 \cdot 2 \mu \mathrm{M}$. This made it possible to generate DB750-adapted T. gondii strains. Kropf et al. (2012) also screened another set of compounds comprised of 10 bis-AIAs, 6 diamidines, 15 newly generated mono-arylimidamides, and $10 \mathrm{di}-$ guanidino analogues against $T$. gondii, and the AIA DB745, exhibiting an $\mathrm{IC}_{50}$ of $0.03 \mu \mathrm{M}$ and most favourable selective toxicity was chosen for further studies. In DB745, each of the 2 phenyl rings is substituted by an $O$-ethyl-moiety. DB745 also efficiently inhibited the proliferation of DB750adapted T. gondii $\left(\mathrm{IC}_{50}=0.07 \mu \mathrm{M}\right)$ and, in contrast to DB750, DB745 had a profound toxic effect on extracellular T. gondii tachyzoites. Adaptation (or resistance) of $T$. gondii to DB745 (up to a concentration of $0.46 \mu \mathrm{M}$ ) was difficult to achieve and feasible only by stepwise increasing the drug concentration over a period of 110 days. Overall, these investigations illustrated the astonishing capacity of $T$. gondii tachyzoites to adapt to environmental changes, at least under in vitro conditions, and open the door to further investigations on the mechanisms of action of these compounds in T. gondii (Kropf et al. 2012).

Neospora caninum is closely related to $T$. gondii, but infection in humans has not been reported, and the parasite owes his importance due to the fact that it represents one of the most important causes of abortion in cattle worldwide (Monney et al. 2011). Neospora isolates with different virulence have been obtained, such as Nc-Liverpool representing a highly virulent isolate, and $\mathrm{Nc}-1$, which is an isolate with lower virulence. Screening for anti-Neospora activity involved the same compounds as for $T$. gondii, and not surprisingly, DB750 and DB745 also emerged as the most effective ones, albeit with differences in terms of $\mathrm{IC}_{50}$ values (e.g. $\mathrm{IC}_{50}$ of $\mathrm{DB} 745=80 \mathrm{~nm}$ for $N$. caninum and $30 \mathrm{~nm}$ for $T$. gondii $(\mathrm{RH})$ tachyzoites (Kropf et al. 2012; Schorer et al. 2012). As for T. gondii, DB750 inhibited proliferation of $N$. caninum tachyzoites, but was not effective against extracellular parasites, while DB745 treatment resulted in inhibition of host cell invasion. A detailed TEM analysis of the effects of DB745 on intracellular N. caninum tachyzoites revealed (Fig. 6) that (i) the integrity of the nuclear membrane was altered in the drug-treated parasites and (ii) most nuclei of drug-treated parasites were devoid of a discernible nucleolus (Fig. 6C). This suggested that DB745 could interfere in the maintenance of the nuclear membrane integrity, possibly interfere in lipid metabolism, and/or in transcriptional activity of these parasites, the latter of which would be potentially in agreement with the postulated mode of action involving DNA-binding. In addition, DB745 treatment resulted in tachyzoites that were fused together at their outer membranes (Fig. 6D). Closer inspection of the contact sites at higher magnification revealed that these were tachyzoites caught in the process of endodyogeny, with the inner membrane layer surrounding both daughter cells and the inner membrane layer either fully present or partially interrupted (Fig. 6E; Schorer et al. 2012). These observations indicated that DB745 could potentially interfere in the formation/metabolism of membranous structures within these parasites. In this context it is interesting to note that a recent study by Ando et al. (2012) demonstrated that treatment with related compounds such as diminazene, pentamidine and $4^{\prime} 66^{\prime}$-diamidino-2-phenylindole (DAPI) increased the permeability of bacterial outer membranes.

Long-term growth assays in the presence of DB745 revealed that the drug had a parasiticidal action against the more virulent $\mathrm{Nc}$-Liverpool isolate, while Nc-1 tachyzoites could adapt to increased concentrations of DB745 (up to $0 \cdot 30 \mu \mathrm{M}$ within a timeframe of 69 days). In vivo studies were performed in mice that were experimentally infected with the $\mathrm{Nc}-1$ isolate, showing that both DB745 and DB750 treatment by intraperitoneal injection of compounds at $2 \mathrm{mg} \mathrm{kg}^{-1}$ for 14 days resulted in a significantly increased number of survivors and significantly decreased cerebral parasite burden compared with non-treated mice (Debache et al. 2011; Schorer et al. 2012). In these experiments, treatments were started 14 days after infection, thus the parasites had already reached the CNS, and thus these compounds most likely were effective in crossing the blood-brain barrier. However, oral application of these two compounds was ineffective (unpublished findings). These initial in vivo results are promising, and 
point out the therapeutic potential of the AIAs DB745 and DB750, and the class of dicationic compounds as a whole, for the treatment of $N$. caninum infections. From the practical point of view on neosporosis in cattle, treatment of congenitally infected calves right after birth could potentially give rise to pathogen-free offspring (Härdi et al. 2006), provided an effective compound can be identified.

Dicationic compounds were also evaluated with respect to their activity against $B$. besnoiti tachyzoites grown in Vero cells. Besnoitia besnoiti is most closely related to $N$. caninum and $T$. gondii. The life cycle of $B$. besnoiti remains mysterious and its definitive host is unknown. Infection assays have shown that $B$. besnoiti infects a variety of potential hosts, but persists only in voles (Basso et al. 2011). Besnoitia besnoiti is transmitted to cattle by haematophagous insects and causes a systemic disease which, during the acute phase with a high parasitaemia, may be associated with fever and fever-associated signs, including abortion. Subsequently, in the chronic stage, the parasite shows a high tropism to the skin, leading to dramatic thickening, hardening and folding, always accompanied by hyperkeratosis, hyperpigmentation and alopecia, and a decrease of milk production is commonly observed. Furthermore, Besnoitia infection in bulls can cause irreversible aspermy and sterility (Jacquiet et al. 2010). The rapidly proliferating $B$. besnoiti tachyzoites can be cultivated as described for $N$. caninum and $T$. gondii. By employing such cultures, drug-screening assays have been performed in order to identify compounds of potential interest for chemotherapeutic treatment, including AIAs (Cortes et al. 2011). Results were different compared with $T$. gondii and $N$. caninum. DB750 $\left(\mathrm{IC}_{50}=0.59 \mu \mathrm{M}\right)$ acted only parasitostatic after 14 days of treatment at $1.7 \mu \mathrm{M}$, while DB811 $\left(\mathrm{IC}_{50}=0.079 \mu \mathrm{M}\right)$ was highly effective, and had a parasiticidal action in vitro (Cortes et al. 2011). Thus, $B$. besnoiti is susceptible to other dicationic compounds, implying that possibly the target(s) in $B$. besnoiti affected by these compounds are different or at least altered compared with $T$. gondii and $N$. caninum. However, the biggest challenge for drug development against these cyst-forming apicomplexans is still to generate compounds that affect the respective bradyzoite stages encapsulated within tissue cysts.

\section{CONCLUDING REMARKS}

In conclusion, amidine-containing compounds represent a versatile class of drugs, with a great potential for the further development of novel chemotherapies against intracellular parasitic protozoa. The hallmarks of the more recently generated compounds are oral bioavailability, metabolic stability, and an increased capacity to pass through biological membranes that makes them uniquely suited to reach parasites that reside and hide within host cells. Some structural modifications also aid in crossing the blood-brain barrier, which is relevant for infections that also affect the CNS. The use of in vitro culture systems has been instrumental for preliminary efficacy assessments and allowed identification of compounds with $\mathrm{IC}_{50} \mathrm{~s}$ in the low nanomolar range, but care must be taken in the respective assessments, since the findings obtained in vitro cannot always be translated into high efficacy in vivo. Pentamidine and many of its derivatives have been designed to bind to the minor groove of DNA, and are found either within the kinetoplast in trypanosomatids or the nucleus in other parasites, but most likely other cellular targets may also be involved. Importantly, the higher potency of AIAs against intracellular agents (like T. cruzi and Leishmania) compared with classical dicationic amidines justify further screening studies also against other parasites like extra-erythrocytic Plasmodium species. The fact that the amidines act against a variety of species living an intracellular lifestyle, and that some are effective in many species while others affect only one, also argues for multiple modes of action. In the future, it will be important to understand the alterations induced by these drugs not only on morphology and ultrastructure, but also on the molecular level. It will be important to understand the molecular changes in gene expression, and to elucidate how these compounds affect the metabolism of their targeted parasites as well as mammalian host cells. This will help to understand their mode of action and to identify the relevant drug targets, information that can be exploited to generate novel and more effective compounds against parasitic diseases.

\section{ACKNOWLEDGEMENTS}

The authors thank Dr Denise da Gama Jaen Batista for providing the fluorescent images in Fig. 2 and Dr S.L. de Castro for revising the text.

\section{FINANCIAL SUPPORT}

The present study was supported by grants from PDTISFiocruz, Fundação Carlos Chagas Filho de Amparo a Pesquisa do Estado do Rio de Janeiro (FAPERJ: APQ1, Estudo de Doenças Negligenciadas Reemergentes-, PENSA RIO, e Apoio a Instituições de Ensino e Pesquisa Sediadas no Estado do Rio de Janeiro), Conselho Nacional de Desenvolvimento Científico e Tecnológico (CNPq), CECAL/Fiocruz and PROEP/Fiocruz. Grant support from the National Institutes of Health, NIAID 064200 (W.D.W. and D.W.B.) is gratefully acknowledged. The Swiss National Science Foundation (grant No. 31003A$127374 / 1)$ is gratefully acknowledged.

\section{REFERENCES}

Alvar, J., Vélez, I. D., Bern, C., Herrero, M., Desjeux, P., Cano, J., Jannin, J. and den Boer, M. (2012). WHO Leishmaniasis control team. Leishmaniasis worldwide and global estimates of its incidence. PLoS One 7, e35671. 
Aly, A. A. and Nour-El-Din, A. M. (2008). Functionality of amidines and amidrazones. Archive for Organic Chemistry 153-194.

Ando, M., Kamei, R., Komagoe, K., Inoue, T., Yamada, K. and Katsu, T. (2012). In situ potentiometric method to evaluate bacterial outer membrane-permeabilizing ability of drugs: example using antiprotozoal diamidines. Fournal of Microbiological Methods 91, 497-500.

Ansede, J.H., Voyksner, R.D., Ismail, M. A., Boykin, D. W., Tidwell, R. R. and Hall, J. E. (2005). In vitro metabolism of an orally active $O$-methyl amidoxime prodrug for the treatment of CNS trypanosomiasis. Xenobiotica 35, 211-226.

Arafa, R. K., Brun, R., Wenzler, T., Tanious, F. A., Wilson, W.D., Stephens, C. E. and Boykin, D. W. (2005). Synthesis, DNA affinity, and antiprotozoal activity of fused ring dicationic compounds and their prodrugs. Fournal of Medicinal Chemistry 48, 5480-5488.

Ashley, J. N., Barber, H.J., Ewins, A. J., Newbery, G. and Self, A. D. H. (1942). A chemotherapeutic comparison of the trypanocidal action of some aromatic diamidines. Fournal of the Chemical Society, 103-116.

Bakunov, S. A., Bakunova, S. M., Ghebru, M., Werbovetz, K. A., Brun, R. and Tidwell, R. R. (2010). Synthesis and antiprotozoal activity of cationic 1,4-diphenyl-1H-1,2,3-triazoles. Fournal of Medicinal Chemistry 53, 254-272.

Bakunova, S. M., Bakunov, S.A., Wenzler, T., Barscz, T., Werbovetz, K. A., Brun, R., Hall, J. E. and Tidwell, R. R. (2007). Synthesis and in vitro antiprotozoal activity of bisbenzofuran cations. Fournal of Medicinal Chemistry 50, 5807-5823.

Bakunova, S. M., Bakunov, S. A., Wenzler, T., Barszcz, T., Werbovetz, K., Brun, R. and Tidwell, R. R. (2009). Synthesis and antiprotozoal activity of pyridyl analogues of pentamidine. Fournal of Medicinal Chemistry 52, 4657-4667.

Banerjee, M., Farahat, A., Kumar, A., Wenzler, T., Brun, R., Munde, M., Wilson, W., Zhu, X., Werbovetz, K. and Boykin, D. (2012). Synthesis, DNA binding and antileishmanial activity of low molecular weight bis arylimidamides. European Fournal of Medicinal Chemistry 55, 449-454.

Barratt, J. L., Harkness, J., Marriott, D., Ellis, J. T. and Stark, D. (2010). Importance of no enteric protozoan infections in immunocompromised people. Clinical Microbiology Reviews 23, 795-836.

Barrett, M. P., Burchmore, R. J. S., Stich, A., Lazzari, J. O., Frasch, A. C. and Cazzulo, J. J. (2003). The trypanosomiases. Lancet 362, 1469-1480.

Barrett, M. P., Boykin, D. W., Brun, R. and Tidwell, R. R. (2007). Human African trypanosomiasis: pharmacological re-engagement with a neglected disease. British fournal of Pharmacology 152, 1155-1171.

Basselin, M., Denise, H., Coombs, G. H. and Barrett, M.P. (2002). Resistance to pentamidine in Leishmania mexicana involves exclusion of the drug from the mitochondrion. Antimicrobial Agents and Chemotherapy 46, 3731-3738.

Basso, W., Schares, G., Gollnick, N. S., Rütten, M. and Deplazes, P. (2011). Exploring the life cycle of Besnoitia besnoiti-experimental infection of putative definitive and intermediate host species. Veterinary Parasitology 178, 223-234.

Batista, D. G. J., Batista, M. M., Oliveira, G. M., Amaral, P. B., Lannes-Vieira, J., Britto, C. C., Junqueira, A., Lima, M. M., Romanha, A. J., Sales Junior, P. A., Stephens, C. E., Boykin, D. W. and Soeiro, M.N.C. $(2010 a)$. Arylimidamide DB766, a potential chemotherapeutic candidate for Chagas' disease treatment. Antimicrobial Agents and Chemotherapy 54, 2940-2952.

Batista, D. G. J., Pacheco, M. G. O., Kumar, A., Branowska, D., Ismail, M. A., Hu, L., Boykin, D. W. and Soeiro, M. N. C. (2010b). Biological, ultrastructural effect and subcellular localization of aromatic diamidines in Trypanosoma cruzi. Parasitology 137, 251-259.

Batista, D. G. J., Batista, M. M., de Oliveira, G. M., Britto, C. C., Rodrigues, A. C., Stephens, C. E., Boykin, D. W. and Soeiro, M. N. C. (2011). Combined treatment of heterocyclic analogues and benznidazole upon Trypanosoma cruzi in vivo. PLoS One 6, e22155.

Bell, C. A., Hall, J.E., Kyle, D.E., Grog1, M., Ohmeng, K. A., Allen, M. A. and Tidwell, R. R. (1990). Structure-activity relationships of analogs of pentamidine against Plasmodium falciparum and Leishmania mexicana amazonensis. Antimicrobial Agents and Chemotherapy 34, 1381-1386.

Berger, B. J., Naiman, N. A., Hall, J. E., Peggins, J., Brewer, T. G. and Tidwell, R. R. (1992). Primary and secondary metabolism of pentamidine by rats. Antimicrobial Agents and Chemotherapy 36, 1825-1831.

Berman, J. and Wyler, D. (1980). An in vitro model for investigation of chemotherapeutic agents in leishmaniasis. Fournal of Infectious Diseases $\mathbf{1 4 2}$, 83-86.

Blagburn, B. L., Sundemann, C. A., Lindsay, D. S., Hall, J. E. and Tidwell, R. R. (1991). Inhibition of Cryptosporidium parvum in neonatal
Hsd:(ICR)BR Swiss mice by polyether ionophores and aromatic amidines. Antimicrobial Agents and Chemotherapy 35, 1520-1523.

Blagburn, B. L., Drain, K. L., Land, T. M., Moore, P. H., Kinard, R. G., Lindsay, D. S., Kumar, A., Shi, J., Boykin, D. W. and Tidwell, R. R. (1998a). Dicationic furans inhibit the development of Cryptosporidium parvum in HSD/ICR suckling Swiss mice. Fournal of Parasitology 84, 851-856.

Blagburn, B. L., Drain, K. L., Land, T. M., Kinard, R. G., Hutton Moore, P., Lindsay, D. S., Patrick, D. A., Boykin, D. W. and Tidwell, R. R. (1998b). Comparative efficacy evaluation of dicationic carbazole compounds, nitazoxanide and paromomycin against Cryptosporidium parvum infections in a neonatal mouse model. Antimicrobial Agents and Chemotherapy 42, 2877-2882.

Boere, R. T., Oakley, R. T. and Reed, R.W. (1987). Preparation of $N, N, N^{\prime}$ tris(trimethylsilyl)amidines; a convenient route to unsubstituted amidines. Fournal of Organometallic Chemistry 331, 161-167.

Boykin, D. W., Kumar, A., Spychala, J., Zhou, M., Lombardy, R. J., Wilson, W. D., Dykstra, C. C., Jones, S. K., Hall, J. E., Tidwell, R. R., Laughton, C., Nunn, C. M. and Neidle, S. (1995). Dicationic diaryl furans as anti-Pneumocystis carinii agents. Fournal of Medicinal Chemistry 38, 912-916.

Boykin, D. W., Kumar, A., Hall, J. E., Bender, B. C. and Tidwell, R. R. (1996). Anti-pneumocystis activity of bis-amidoximes and bis-O-alkylamidoximes prodrugs. Bioorganic and Medicinal Chemistry Letters 6, 3017-3020.

Branowska, D., Farahat, A. A., Kumar, A., Wenzler, T., Brun, R., Liu, Y., Wilson, W.D. and Boykin, D.W. (2010). Synthesis and antiprotozoal activity of 2,5-bis[amidinoaryl]thiazoles. Bioorganic and Medicinal Chemistry 18, 3551-3558.

Bray, P. G., Barret, M. P., Ward, S. A. and De Koning, H. P. (2003). Pentamidine uptake and resistance in pathogenic protozoa: past, present and future. Trends in Parasitology 19, 232-239.

Bustamante, J. M., Bixby, L. M. and Tarleton, R. L. (2008). Druginduced cure drives conversion to a stable and protective CD8+ T central memory response in chronic Chagas disease. Nature Medicine 14, 542-550. Carlton, J. (2003). The Plasmodium vivax genome sequencing project. Trends in Parasitology 19, 227-231.

Chackal-Catoen, S., Mao, Y., Wilson, W. D., Wenzler, T., Brun, R. and Boykin, D. W. (2006). Dicationic DNA-targeted antiprotozoal agents: naphthalene replacement of benzimidazole. Bioorganic and Medicinal Chemistry 14, 7434-7445.

Chowdhury, A. R., Bakshi, R., Wang, J., Yildirir, G., Liu, B., Pappas-Brown, V., Tolun, G., Griffith, J.D., Shapiro, T.A., Jensen, R. E. and Englund, P. T. (2010). The killing of African trypanosomes by ethidium bromide. PLoS Pathogens 6, 1-14.

Clement, B. and Raether, W. (1985). Amidoximes of pentamidine: synthesis, trypanocidal and leishmanicidal activity. Arzneimittelforschung 35, 1009-1014.

Collar, C., Zhu, X., Werbovetz, K., Boykin, D. and Wilson, W. (2011). Governing inhibition of arylimidamides against Leishmania: conservative computational modeling to improve chemotherapies. Bioorganic and Medicinal Chemistry 19, 4552-4561.

Cortes, H. C., Müller, N., Boykin, D., Stephens, C.E. and Hemphill, A. (2011). In vitro effects of arylimidamides against Besnoitia besnoiti infection in Vero cells. Parasitology 138, 583-592.

Cory, M., Tidwell, R. R. and Fairly, T. A. (1992). Structure and DNA binding activity of analogues of 1,5-bis(4-amidinophenoxy)pentamidine (Pentamidine). Fournal of Medicinal Chemistry 35, 431-438.

Coura, J. R. and Borges-Pereira, J. (2012). Chagas disease. What is known and what should be improved: a systemic review. Revista Sociedade Brasileira de Medicina Tropical 45, 286-296.

Croft, S. and Brazil, R. (1982). Effect of pentamidine isethionate on the ultrastructure and morphology of Leishmania mexicana amazonensis in vitro. Annals of Tropical Medicine and Parasitology 76, 37-43.

Croft, S. and Olliaro, P. (2011). Leishmaniasis chemotherapy - challenges and opportunities. Clinical Microbiology and Infection 17, 1478-1483.

Daliry, A., Pires, M. Q., Silva, C.F., Pacheco, R.S., Munde, M., Stephens, C. E., Kumar, A., Ismail, M. A., Liu, Z., Farahat, A. A. Akay, S., Som, P., Hu, Q., Boykin, D.W., Wilson, W. D., De Castro, S. L. and Soeiro, M. N. C. (2011). The trypanocidal activity of amidine compounds does not correlate with their binding affinity to Trypanosoma cruzi kinetoplast DNA. Antimicrobial Agents and Chemotherapy 55, 4765-4773.

Das, B.P. and Boykin, D. W. (1977). Synthesis and antiprotozoal activity of 2,5-Bis-(4-guanylphenyl)furans. Fournal of Medicinal Chemistry 20, 531-536.

Das, V., Siddiqui, N., Pandey, K., Singh, V., Topno, R., Singh, D., Verma, R., Ranjan, A., Sinha, P. and Das, P. (2009). A controlled, 
randomized nonblinded clinical trial to assess the efficacy of amphotericin B deoxycholate as compared to pentamidine for the treatment of antimony unresponsive visceral leishmaniasis cases in Bihar, India. Therapeutics and Clinical Risk Management 5, 117-124.

Da Silva, C.F., Batista, M. M., Batista, D. G., de Souza, E. M. da Silva, P. B., de Oliveira, G. M., Meuser, A. S., Shareef, A. R. Boykin, D. W. and Soeiro, M. N. C. (2008). In vitro and in vivo studies of the trypanocidal activity of a diarylthiophene diamidine against Trypanosoma cruzi. Antimicrobial Agents and Chemotherapy 52, 3307-3314. Da Silva, C. F., Junqueira, A., Lima, M. M., Romanha, A. J. Sales Junior, P. A., Stephens, C. E., Som, P., Boykin, D.W. and Soeiro, M. N. C. (2011a). In vitro trypanocidal activity of DB745B and other novel arylimidamides against Trypanosoma cruzi. Fournal of Antimicrobial Chemotherapy 66, 1295-1297.

Da Silva, C.F., Daliry, A., Silva, P.B., Akay, S., Banerjee, M. Farahat, A. A., Mary, K., Fisher, M. K., Hu, L., Kumar, A., Liu, Z. Stephens, C. E., Boykin, D. W. and Soeiro, M. N. C. (2011b). The efficacy of arylimidamides against Trypanosoma cruzi in vitro. Parasitology $\mathbf{1 3 8}$ 1863-1869.

Da Silva, C.F., Batista, D. G., Oliveira, G. M., De Souza, E. M., Hammer, E. R., Silva, P. B., Anissa Daliry, A., Siciliano, J. A., Britto, C., Rodrigues, A. C. M., Liu, Z., Farahat, A. A., Kumar, A. Boykin, D. W. and Soeiro, M. N.C. (2012). In vitro and in vivo investigation of the efficacy of arylimidamide DB1831 and its mesylated salt form DB1965 - against Trypanosoma cruzi infection. PLoS One 7 , e30356

De Castro, S. L., Batista, D. G., Batista, M. M., Batista, W., Daliry, A., de Souza, E. M., Menna-Barreto, R. F., Oliveira, G. M., Salomão, K. Silva, C. F., Silva, P. B. and Soeiro, M. N. C. (2011). Experimenta chemotherapy for Chagas disease: a morphological, biochemical, and proteomic overview of potential Trypanosoma cruzi targets of amidines derivatives and naphthoquinones. Molecular Biology International. Specia Issue Target Identification and Intervention Strategies against Kinetoplastid Protozoan Parasites. doi 10.4061/2011/306928.

De Souza, E. M., Lansiaux, A., Bailly, C., Wilson, W. D., Hu, Q. Boykin, D. W., Batista, M. M., Araújo-Jorge, T. C. and Soeiro, M. N. C. (2004). Phenyl substitution of furamidine markedly potentiates its antiparasitic activity against Trypanosoma cruzi and Leishmania amazonensis. Biochemical Pharmacology 15, 593-600.

De Souza, E. M., Menna-Barreto, R., Araújo-Jorge, T. C., Kumar, A., Hu, Q., Boykin, D. W. and Soeiro, M. N. C. (2006). Antiparasitic activity of aromatic diamidines is related to apoptosis-like death in Trypanosoma cruzi. Parasitology 133, 75-79.

De Souza, E. M., Oliveira, G. M. and Soeiro, M. C. N. (2007) Electrocardiographic findings in acutely and chronically T. cruzi-infected mice treated by a phenyl-substituted analogue of furamidine DB569. Drus Target Insights 2, 61-69.

de Waal, D. T. and Combrink, M. P. (2006). Live vaccines against bovine babesiosis. Veterinary Parasitology 138, 88-96.

Debache, K., Guionaud, C., Kropf, C., Boykin, D. W., Stephens, C. E. and Hemphill, A. (2011). Experimental treatment of Neospora caninuminfected mice with the arylimidamide DB750 and the thiazolide nitazoxanide. Experimental Parasitology 129, 95-100.

Delves, M., Plouffe, D., Scheurer, C., Meister, S., Wittlin, S. Winzeler, E. A., Sinden, R. E. and Leroy, D. (2012). The activities of current antimalarial drugs on the life cycle stages of Plasmodium: a comparative study with human and rodent parasites. PLoS Medicine 9 , e1001169.

Dias, J. C. (2009). Elimination of Chagas disease transmission: perspectives. Memorias do Instituto Oswaldo Cruz 104, 41-45.

Donnelly, H., Bernard, E. M., Rothkotter, H., Gold, J.W. and Armstrong, D. (1988). Distribution of pentamidine in patients with AIDS. Fournal of Infectious Diseases 157, 985-989.

Dubey, J. P. (2009). History of the discovery of the life cycle of Toxoplasma gondii. International Fournal for Parasitology 39, 877-882.

Eloy, F. and Lenaers, R. (1962). The chemistry of amidoximes and related compounds. Chemical Reviews 62, 155-183.

Farahat, A. A., Kumar, A., Say, M., Barghash, A. E. M., Goda, F. E., Eisa, H. M., Wenzler, T., Brun, R., Liu, Y., Mickelson, L., Wilson, W. D. and Boykin, D. W. (2010). Synthesis, DNA binding, fluorescence measurements and anti-parasitic activity of DAPI related diamidines. Bioorganic and Medicinal Chemistry 18, 557-566.

Farahat, A. A., Paliakov, E., Kumar, A., Barghash, A. E. M. Goda, F. E., Eisa, H. M., Wenzler, T., Brun, R., Yang Liu, Y. Wilson, W. D. and Boykin, D. W. (2011). Exploration of larger central ring linkers in furamidine analogues: synthesis and evaluation of their DNA binding, antiparasitic and fluorescence properties. Bioorganic and Medicinal Chemistry 19, 2156-2167.
Feldman, D. M., Timms, D. and Borgida, D. F. (2010). Toxoplasmosis, parvovirus, and cytomegalovirus in pregnancy. Clinical Laboratory Medicine 30, 709-720.

Gebre-Hiwot, A., Tadesse, G., Croft, S. and Frommel, D. (1992). An in vitro model for screening antileishmanial drugs: the human leukaemia monocyte cell line, THP-1. Acta Tropica 51, 237-245.

Generaux, C. N., Ainslie, G. R., Bridges, A.S., Ismail, M. A., Boykin, D. W., Tidwell, R. R., Thakker, D. R. and Paine, M.F. (2013). Compartmental and enzyme kinetic modeling to elucidate the biotransformation pathway of a centrally acting antitrypanosomal prodrug. Drug Metabolism and Disposition 41, 518-528.

Goa, K. L. and Campoli-Richards, D. M. (1987). Pentamidine isethionate. A review of its antiprotozoal activity, pharmacokinetics properties and therapeutic use in Pneumocystis carinii pneumonia. Drugs 33, 242-258.

Goodsell, D. and Dickerson, R. E. (1986). Isohelical analysis of DNA groove-binding drugs. Fournal of Medicinal Chemistry 29, 727-733.

Hanson, W., Chapman, W. and Kinnamon, K. (1977). Testing of drugs for antileishmanial activity in golden hamsters infected with Leishmania donovani. International Fournal for Parasitology 7, 443-447.

Härdi, C., Haessig, M., Sager, H., Greif, G., Staubli, D. and Gottstein, B. (2006). Humoral immune reaction of newborn calves congenitally infected with Neospora caninum and experimentally treated with toltrazuril. Parasitology Research 99, 534-540.

Hemphill, A., Esposito, M. and Müller, J. (2006). Nitazoxanide, a broadspectrum thiazolide anti-infective agent for the treatment of gastrointestinal infections. Expert Opinion in Pharmacotherapy 7, 953-964.

Henriquez, F. L., Woods, S., Cong, H., McLeod, R. and Roberts, C. W. (2010). Immunogenetics of Toxoplasma gondii informs vaccine design. Trends in Parasitology 26, 550-555.

Hu, L. and Boykin, D. W. (2009). A novel and convenient synthesis of 'reversed' diamidino 2,5-aryl and 2,5-azaheterocycle-substituted furans. Synthesis 13, 2143-2145.

Hu, L., Arafa, R. K., Ismail, M. A., Wenzler, T., Brun, R., Munde, M. Wilson, W. D., Nzimiro, S., Samyesudhas, S., Werbovetz, K. A. and Boykin, D. W. (2008). Azaterphenyl diamidines as antileishmanial agents. Bioorganic and Medicinal Chemistry Letters 18, 247-251.

Hu, L., Arafa, R. K., Ismail, M. A., Patel, A., Munde, M., Wilson, W.D., Wenzler, T., Brun, R. and Boykin, D. W. (2009). Synthesis and activity of azaterphenyl diamidines against Trypanosoma brucei rhodesience and Plasmodium falciparum. Bioorganic and Medicinal Chemistry 17, 6651-6658.

Hu, R., Kent, A., Adams, E., van der Veer, C., Sabajo, L., Mans, D., de Vries, H., Schallig, H. and Fat, R. (2012). Case report: first case of cutaneous leishmaniasis caused by Leishmania (Viannia) braziliensis in Suriname. American fournal of Tropical Medicine and Hygiene 86, 825-827. Huang, T., Vanden Eynde, J., Mayence, A., Donkor, I., Khan, S. and Tekwani, B. (2006). Anti-plasmodial and anti-leishmanial activity of conformationally restricted pentamidine congeners. Fournal of Pharmacy and Pharmacology 58, 1033-1042.

Ismail, M. A., Brun, R., Easterbrook, J. D., Tanious, F. A., Wilson, W. D. and Boykin, D. W. (2003). Synthesis and antiprotozoal activity of aza-analogues of furamidine. Fournal of Medicinal Chemistry 46, 4761-4769.

Ismail, M. A., Brun, R., Wenzler, T., Tanious, F. A., Wilson, W. D. and Boykin, D. W. (2004). Novel dicationic imidazo[1,2-a]pyridines and 5,6,7,8-tetrahydro-imidazo[1,2-a]pyridines as antiprotozoal agents. Fournal of Medicinal Chemistry 47, 3658-3664.

Ismail, M. A., Batista-Parra, A., Miao, Y., Wilson, W. D., Wenzler, T., Brun, R. and Boykin, D. W. (2005). Dicationic near-linear biphenylbenzimidazole derivatives as DNA-targeted antiprotozoal agents. Bioorganic and Medicinal Chemistry 13, 6718-6726.

Ismail, M. A., Arafa, R.K., Reto, B. R., Wenzler, T., Miao, Y., Wilson, W.D., Generaux, C., Bridges, A., Hall, J.E. and Boykin, D. W. (2006). Synthesis, DNA affinity and antiprotozoal activity of linear dications: terphenyl diamidines and analogues. Fournal of Medicinal Chemistry 49, 5324-5332.

Ismail, M. A., Arafa, R. K., Wenzler, T., Brun, R., Tanious, F. A. Wilson, W. D. and Boykin, D. W. (2008). Synthesis and antiprotozoal activity of novel bis-benzamidino imidazo[1,2-a]pyridines and 5,6,7,8tetrahydro-imidazo[1,2-a]pyridines. Bioorganic and Medicinal Chemistry 16, 683-691.

Ismail, M. A., El Bialy, S. A., Brun, R., Wenzler, T., Nanjunda, R., Wilson, W. D. and Boykin, D. W. (2011). Dicationic phenyl-2, 2'bichalcophenes and analogues as antiprotozoal agents. Bioorganic and Medicinal Chemistry 19, 978-984.

Jacquiet, P., Liénard, E. and Franc, M. (2010). Bovine besnoitiosis: epidemiological and clinical aspects. Veterinary Parasitology 174, 30-36. 
Judkins, B. D., Allen, D. G., Cook, T. A., Evans, B. and Sardharwala, T. E. (1996). A versatile synthesis of amidines from nitriles via amidoximes. Synthetic Communications 26, 4351-4367.

King, H., Lourie, E. M. and Yorke, W. (1937). New trypanocidal substances. Lancet II, 1360-1363.

Kjemtrup, A. M. and Conrad, P. A. (2000). Human babesiosis: an emerging tick-borne disease. International fournal for Parasitology 30, 1323-1337.

Klingbeil, M. M., Drew, M.E., Liu, Y., Morris, J. C., Motyka, S. A., Saxowsky, T. T., Wang, Z. and Englund, P. T. (2001). Unlocking the secrets of trypanosome kinetoplast DNA network replication. Protist 152, 255-262.

Kotthaus, J., Schade, D., Schwering, U., Hungeling, H., Muller-Fielitz, H., Raasch, W. and Clement, B. (2011). New prodrugs of the antiprotozoal drug pentamidine. Chem Med Chem 6, 2233-2242.

Kropf, C., Debache, K., Rampa, C., Barna, F., Schorer, M., Stephens, C. E., Ismail, M. A., Boykin, D. W. and Hemphill, A. (2012). The adaptive potential of a survival artist: characterization of the in vitro interactions of Toxoplasma gondii tachyzoites with di-cationic compounds in human fibroblast cell cultures. Parasitology 139, 208-220. Lai, D. H., Hashimi, H., Lun, Z. R., Ayala, F. J. and Lukes, J. (2008). Adaptations of Trypanosoma brucei to gradual loss of kinetoplast DNA: Trypanosoma equiperdum and Trypanosoma evansi are petite mutants of T. brucei. Proceedings of the National Academy of Sciences USA 105, 1999-2004

Lallemand, M., Villeneuve, A., Belda, J. and Dubreuil, P. (2006). Field study of the efficacy of halofuginone and decoquinate in the treatment of cryptosporidiosis in veal calves. Veterinary Record 159, 672-676.

Lanteri, C. A., Stewart, M. L., Brock, J. M., Alibu, V.P., Meshnick, S. R., Tidwell, R. R. and Barrett, M. P. (2006). Roles for the Trypanosoma brucei P2 transporter in DB75 uptake and resistance. Molecular Pharmacology 70, 1585-1592.

Leepin, A., Stüdli, A., Brun, R., Stephens, C. E., Boykin, D. W. and Hemphill, A. (2008). Host cells participate in the in vitro effects of novel diamidine analogues against tachyzoites of the intracellular apicomplexan parasites Neospora caninum and Toxoplasma gondii. Antimicrobial Agents and Chemotherapy 52, 1999-2008.

Lefay, D., Naciri, M., Poirier, P. and Chermette, R. (2001). Efficacy of halofuginone lactate in the prevention of cryptosporidiosis in suckling calves. Veterinary Record 148, 108-112.

Lepesheva, G. I. and Waterman, M. R. (2011). Sterol 14alpha-demethylase (CYP51) as a therapeutic target for human trypanosomiasis and leishmaniasis. Current Topics in Medicinal Chemistry 11, 2060-2071.

Lindsay, D. S., Blagburn, B. L., Hall, J. E. and Tidwell, R. R. (1991). Activity of pentamidine and pentamidine analogs against Toxoplasma gondii in cell cultures. Antimicrobial Agents and Chemotherapy 35, 1914-1916.

Lown, J.W. (1994). DNA recognition by lexitropsins, minor groove binding agents. Fournal of Molecular Recognition 7, 79-88.

Macharia, J., Bourdichon, A. and Gicheru, M. (2004). Efficacy of

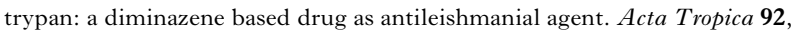
267-272.

Marin-Neto, J. A. and Rassi, A., Jr. (2009). Update on Chagas heart disease on the first centenary of its discovery. Revista Espanhola de Cardiologia 62, 1211-1216.

Mäser, P, Wittlin, S., Rottmann, M., Wenzler, T., Kaiser, M. and Brun, R. (2012). Antiparasitic agents: new drugs on the horizon. Current Opinion in Pharmacology 12, 562-566.

Mathis, A. M., Holman, J. L., Sturk, L. M., Ismail, M. A., Boykin, D. W., Tidwell, R. R. and Hall, J. E. (2006). Accumulation and intracellular distribution of antitrypanosomal diamidine compounds DB75 and DB820 in African trypanosomes. Antimicrobial Agents and Chemotherapy 50, 2185-2191.

Mathis, A. M., Bridges, A. S., Ismail, M. A., Kumar, A., Francesconi, I., Anbazhagan, M., Hu, Q., Tanious, F. A., Wenzler, T., Saulter, J., Wilson, W. D., Brun, R., Boykin, D. W., Tidwell, R. R. and Hall, J. E. (2007). Diphenyl furans and aza analogs: effects of structural modification on in vitro activity, DNA binding, and accumulation and distribution in trypanosomes. Antimicrobial Agents and Chemotherapy 51, 2801-2810.

Mayence, A., Vanden Eynde, J., LeCour, L. J., Walker, L., Tekwani, B. and Huang, T. (2004). Piperazine-linked bisbenzamidines: a novel class of antileishmanial agents. European fournal of Medicinal Chemistry 39, 547-553.

McKerrow, J.H., Doyle, P.S., Engel, J. C., Podust, L. M., Robertson, S. A., Ferreira, R., Saxton, T., Arkin, M., Kerr, I. D., Brinen, L. S. and Craik, C. S. (2009). Two approaches to discovering and developing new drugs for Chagas disease. Memorias do Instituto Oswaldo Cruz 104, 263-269.
Mdachi, R. E., Thuita, J. K., Kagira, J. M., Ngotho, J. M., Murilla, G. A., Ndung'u, J.M., Tidwell, R. R., Hall, J. E. and Brun, R. (2009). Efficacy of the novel diamidine compound 2,5-Bis(4amidinophenyl)- furan-bis- $O$-methlylamidoxime (Pafuramidine, DB289) against Trypanosoma brucei rhodesiense infection in vervet monkeys after oral administration. Antimicrobial Agents and Chemotherapy 53, 953-957.

Miao, Y., Lee, M., Batista-Parra, A., Ismail, M. A., Neidle, S., Boykin, D. W. and Wilson, W. D. (2005). Out of shape DNA minor groove binders induced fit interactions of heterocyclic dications with the DNA minor groove. Biochemistry 44, 14701-14708.

Midgley, I., Fitzpatrick, K., Taylor, L. M., Houchen, T. L. Henderson, S. J., Wright, S. J., Cybulski, Z. R., John, B. A., McBurney, A., Boykin, D.W. and Trendler, K. L. (2007). Pharmacokinetics and metabolism of the prodrug DB289 (2,5-bis[4-( $N$ methoxyamidino)phenyl]furan monomaleate) in rat and monkey and its conversion to the antiprotozoal/antifungal drug DB75 (2,5-bis(4-guanylphenyl)furan dihydrochloride). Drug Metabolism and Disposition 35, 955-967.

Molina, J., Martins-Filho, O., Brener, Z., Romanha, A. J. Loebenberg, D. and Urbina, J.A. (2000). Activities of the triazole derivative SCH 56592 (posaconazole) against drug-resistant strains of the protozoan parasite Trypanosoma (Schizotrypanum) cruzi in immunocompetent and immunosuppressed murine hosts. Antimicrobial Agents and Chemotherapy 44, 150-155.

Monney, T., Debache, K. and Hemphill, A. (2011). Vaccines against a major cause of abortion in cattle, Neospora caninum infection. Animals 1, 306-325.

Müller, J. and Hemphill, A. (2013). In vitro culture systems for the study of apicomplexan parasites in farm animals. International fournal for Parasitology 43, 115-124.

Nehrbass-Stüdli, A., Boykin, D., Tidwell, R. R. and Brun, R. (2011). Novel diamidines with activity against Babesia divergens in vitro and Babesia microti in vivo. Antimicrobial Agents and Chemotherapy 55, 3439-3445.

Neves, L., Talhari, A., Gadelha, E., Silva Júnior, R., Guerra, J., Ferreira, L. and Talhari, S. (2011). A randomized clinical trial comparing meglumine antimoniate, pentamidine and amphotericin B for the treatment of cutaneous leishmaniasis by Leishmania guyanensis. Anais Brasileiros de Dermatologia 86, 1092-1101.

Nguygen, B., Lee, M.P., Hamelberg, D., Joubert, A., Bailly, C., Brun, R., Neidle, S. and Wilson, W. D. (2002). Strong binding in the DNA minor groove by an aromatic diamidine with a shape that does not match the curvature of the groove. Fournal of the American Chemical Society 124, 13680-13681.

Nguygen, B., Hamelberg, D., Bailly, C., Colson, P., Stanek, J., Brun, R., Neidle, S. and Wilson, W.D. (2004). Characterization of a novel DNA minor-groove complex. Biophysical fournal 86, 1028-1041.

Nguyen, B., Boykin, D.W. and Wilson, W.D. (2007). DNA minor groove interactions of antiparasitic diamidines: re-evaluation of the crescentshape concept in groove-binding. In Synthetic and Biophysical Studies of DNA Binding Compounds (ed. Lee, M. and Strekowski, L.) Chap 2. Transworld Research Network, Trivandrum-695023, Kerala, India.

Olliaro, P., Guerin, P., Gerstl, S., Haaskjold, A., Rottingen, J. and Sundar, S. (2005). Treatment options for visceral leishmaniasis: systematic review of clinical studies done in India, 1980-2004. Lancet Infectious Diseases 5, 763-774

Pacheco, M. G., da Silva, C.F., de Souza, E. M., Batista, M. M., da Silva, P. B., Kumar, A., Stephens, C.E., Boykin, D.W. and Soeiro, M. N. C. (2009). Trypanosoma cruzi: activity of heterocyclic cationic molecules in vitro. Experimental Parasitology 123, 73-80.

Paine, M.F., Wang, M.Z., Generaux, C. N., Boykin, D.W., Wilson, W. D., De Koning, H. P., Olson, C. A., Pohlig, G., Burri, C., Brun, R., Murilla, G. A., Thuita, J. K., Barrett, M. P. and Tidwell, R. R. (2010). Diamidines for human African trypanosomiasis. Current Opinions in Investigational Drugs 11, 876-883.

Picado, A., Rijal, S., Sundar, S. and Boelaert, M. (2012). Visceral leishmaniasis treatment in the Indian subcontinent: how to reach the most vulnerable. Expert Review of Anti-Infective Therapy 10, 839-841.

Pinner, A. and Klein, F. (1877). Umwandlung der nitrile in imide Berichte der deutschen chemischen Gesellschaft 10, 1889-1897.

Purfield, A.E., Tidwell, R.R. and Meshnick, S. R. (2009). The diamidine DB75 targets the nucleus of Plasmodium falciparum. Malaria Fournal 8, 104

Reid, C., Farahat, A., Zhu, X., Pandharkar, T., Boykin, D. and Werbovetz, K. (2012). Antileishmanial bis-arylimidamides: DB766 analogs modified in the linker region and bis-arylimidamide structureactivity relationships. Bioorganic and Medicinal Chemistry Letters 22, 6806-6810. 
Rocha, M. O., Teixeira, M. M. and Ribeiro, A. L. (2007). An update on the management of Chagas cardiomyopathy. Expert Review Anti Infective Therapy 5, 727-743.

Roger, R. and Neilson, D. G. (1961). The chemistry of imidates. Chemical Reviews 61, 179-211.

Romanha, A. J., Castro, S.L., Soeiro, M. N. C., Lannes-Vieira, J., Ribeiro, I., Talvani, A., Bourdin, B., Blum, B., Olivieri, B., Zani, C. Spadafora, C., Chiari, E., Chatelain, E., Chaves, G., Calzada, J. E., Bustamante, J. M., Freitas-Junior, L. H., Romero, L. I., Bahia, M. T., Lotrowska, M., Soares, M., Andrade, S. G., Armstrong, T. Degrave, W. and Andrade, Z. A. (2010). In vitro and in vivo experimental models for drug screening and development for Chagas disease. Memórias do Instuto Oswaldo Cruz 105, 233-238.

Sands, M., Kron, M. A. and Brown, R. A. (1985). Pentamidine: a review. Reviews in Infectious Diseases 7, 625-634.

Saulter, J.Y. (2005). Permeability and Metabolism of Potential Prodrugs for the Antimicrobial Agent 2,5 bis(4-amidinophenyl)furan (DB75) [3170543]. The University of North Carolina at Chapel Hill, Chapel Hill, NC, USA.

Saulter, J.Y., Kurian, J.R., Trepanier, L.A., Tidwell, R. R., Bridges, A.S., Boykin, D. W., Stephens, C. E., Anbazhagan, M. and Hall, J. E. (2005). Unusual dehydroxylation of antimicrobial amidoxime prodrugs by cytochrome b5 and NADH cytochrome b5 reductase. Drug Metabolism and Disposition 33, 1886-1893.

Schnaufer, A., Panigrahi, A. K., Panicucci, B., Igo, R. P., Jr., Wirtz, E. Salavati, R. and Stuart, K. (2001). An RNA ligase essential for RNA editing and survival of the bloodstream form of Trypanosoma brucei. Science 291, 2159-2162

Schnaufer, A., Domingo, G. J. and Stuart, K. (2002). Natural and induced dyskinetoplastic trypanosomatids: how to live without mitochondrial DNA. International fournal for Parasitology 32, 1071-1084.

Schnaufer, A., Clark-Walker, G. D., Steinberg, A. G. and Stuart, K. (2005). The F1-ATP synthase complex in bloodstream stage trypanosomes has an unusual and essential function. EMBO Fournal 24, 4029-4040.

Schnyder, M., Kohler, L., Hemphill, A. and Deplazes, P. (2009) Prophylactic and therapeutic efficacy of nitazoxanide against Cryptosporidium parvum in experimentally challenged neonatal calves. Veterinary Parasitology 160, 149-154.

Schorer, M., Debache, K., Barna, F., Monney, T., Boykin, D. W., Stephens, C. E. and Hemphill, A. (2012). Di-cationic arylimidamides act against Neospora caninum tachyzoites by interference in membrane structure and nucleolar integrity and are active against challenge infection in mice. International Fournal for Parasitology: Drugs and Drug Resistance 2, 109-120.

Shapiro, T. A. and Englund, P. T. (1990). Selective cleavage of kinetoplast DNA minicircles promoted by antitrypanosomal drugs. Proceedings of the National Academy of Sciences USA 87, 950-954.

Shapiro, T. A. and Englund, P. T. (1995). The structure and replication of kinetoplast DNA. Annual Review of Microbiology 49, 117-143.

Shriner, R. 1. and Neumann, F. W. (1944). The chemistry of the amidines. Chemical Reviews 35, 351-425.

Silva, C.F., Batista, M. M., Mota, R.A., de Souza, E. M., Stephens, C. E., Som, P., Boykin, D. W. and Soeiro, M. N. C. (2007) Activity of 'reversed' diamidines against Trypanosoma cruzi 'in vitro'. Biochemical Pharmacology 15, 1939-1946.

Singh, N., Kumar, M. and Singh, R. K. (2012). Leishmanaiasis: current status of available drugs and new potential drug targets. Asian Pacific Fournal of Tropical Medicine 485-497.

Soeiro, M. N. and de Castro, S. L. (2009). Trypanosoma cruzi targets for new chemotherapeutic approaches. Expert Opinion on Therapeutic Targets 13, 105-121

Soeiro, M. N., De Souza, E. M., Stephens, C. E. and Boykin, D. W. (2005). Aromatic diamidines as antiparasitic agents. Expert Opinion on Investigational Drugs 14, 957-972.

Soeiro, M. N., de Castro, S. L., de Souza, E. M., Batista, D. G., Silva, C. F. and Boykin, D.W. (2008). Diamidine activity against trypanosomes: the state of the art. Current Molecular Pharmacology 1, 151-161.

Soeiro, M. N. C. and de Castro, S. L. (2011). Screening of potential antiTrypanosoma cruzi candidates: in vitro and in vivo studies. Open Medicinal Chemistry fournal 5, 21-30.

Stadelmann, B., Kuster, T., Scholl, S., Barna, F., Kropf, C., Keiser, J., Boykin, D. W., Stephens, C. E. and Hemphill, A. (2011). In vitro efficacy of di-cationic compounds (pentamidine analogs) and mefloquine-enantiomers against Echinococcus multilocularis metacestodes. Antimicrobial Agents and Chemotherapy 55, 4866-4872.

Stead, A. M., Bray, P. G., Edwards, I. G., De Koning, H.P., Elford, B. C., Stocks, P.A. and Ward, S. A. (2001). Diamidine compounds: selective uptake and targeting in Plasmodium falciparum Molecular Pharmacology 59, 1298-1306.

Steck, E., Kinnamon, K., Rane, D. and Hanson, W. (1981) Leishmania donovani, Plasmodium berghei, Trypanosoma rhodesiense: antiprotozoal effects of some amidine types. Experimental Parasitology 52, 1981. Stephens, C. E., Tanious, F., Kim, S., Wilson, W. D., Schell, W. A., Perfect, J. R., Franzblau, S. G. and Boykin, D. W. (2001). Diguanidino and 'Reversed' diamidino 2,5-Diarylfurans as antimicrobial agents. Fournal of Medicinal Chemistry 44, 1741-1748.

Stephens, C., Brun, R., Salem, M., Werbovetz, K., Tanious, F., Wilson, W. and Boykin, D. (2003). The activity of diguanidino and 'reversed' diamidino 2,5-diarylfurans versus Trypanosoma cruzi and Leishmania donovani. Bioorganic Medicinal and Chemistry Letters 13, 2065-2069.

Stewart, M. L., Krishna, S., Burchmore, R. J., Brun, R., de Koning, H.P., Boykin, D. W., Tidwell, R. R., Hall, J. E. and Barrett, M.P. (2005). Detection of arsenical drug resistance in Trypanosoma brucei with a simple fluorescence test. Lancet 366, 486-487.

Thuita, J. K., Wang, M. Z., Kagira, J. M., Denton, C. L., Paine, M. F., Mdachi, R. E., Murilla, G. A., Ching, S., Boykin, D. W., Tidwell, R. R., Hall, J. E. and Brun, R. (2012). Pharmacology of DB844, an orally active aza analogue of pafuramidine, in a monkey model of second stage human African trypanosomiasis. PLoS Neglected Tropical Diseases 6, e1734.

Tidwell, R. R. and Boykin, D. W. (2003) Dicationic DNA minor groove binders as antimicrobial agents. In Small Molecule DNA and RNA Binders: From Synthesis to Nucleic Acid Complexes (ed. Demeunynck, M., Bailly, C. and Wilson, W. D.), Vol. 2, pp. 414-460. Wiley-VCH, New York, USA. Urbina, J. A., Payares, G., Contreras, L. M., Liendo, A., Sanoja, C., Molina, J., Piras, M., Piras, R., Perez, N., Wincker, P. and Loebenberg, D. (1998). Antiproliferative effects and mechanism of action of SCH 56592 against Trypanosoma (Schizotrypanum) cruzi: in vitro and in vivo studies. Antimicrobial Agents and Chemotherapy 42, 1771-1777.

Urbina, J. A., Payares, G., Sanoja, C., Lira, R. and Romanha, A. J. (2003). In vitro and in vivo activities of ravuconazole on Trypanosoma cruzi, the causative agent of Chagas disease. International Fournal of Antimicrobial Agents 21, 27-38

van der Meide, W., Sabajo, L., Jensema, A., Peekel, I., Faber, W., Schallig, H. and Fat, R. (2009). Evaluation of treatment with pentamidine for cutaneous leishmaniasis in Suriname. International fournal of Dermatology 48, 52-58.

Vial, H. J. and Gorenflot, A. (2006). Chemotherapy against babesiosis. Veterinary Parasitology 138, 147-160.

Wang, M. Z., Saulter, J. Y., Usuki, E., Cheung, Y.L., Hall, M., Bridges, A. S., Loewen, G., Parkinson, O. T., Stephens, C. E. Allen, J. L., Zeldin, D. C., Boykin, D. W., Tidwell, R. R., Parkinson, A., Paine, M. F. and Hall, J. E. (2006). CYP4F enzymes are the major enzymes in human liver microsomes that catalyze the O-demethylation of the antiparasitic prodrug DB289 [2,5-bis(4-amidinophenyl)furan-bis-O-methylamidoxime]. Drug Metabolism and Disposition 34, 1985-1994.

Wang, M.Z., Wu, J. Q., Bridges, A.S., Zeldin, D. C., Kornbluth, S., Tidwell, R. R., Hall, J.E. and Paine, M. F. (2007). Human enteric microsomal CYP4F enzymes $O$-demethylate the anti-parasitic prodrug pafuramidine. Drug Metabolism Dispose 35, 2067-2075.

Wang, M.Z., Zhu, X., Srivastava, A., Liu, Q., Sweat, J. M., Pandharkar, T., Stephens, C. E., Riccio, E., Parman, T., Munde, M. Mandal, S., Madhubala, R., Tidwell, R. R., Wilson, W. D. Boykin, D. W., Hall, J. E., Kyle, D. E. and Werbovetz, K. A. (2010). Novel arylimidamides for the treatment of visceral leishmaniasis. Antimicrobial Agents and Chemotherapy 54, 2507-2516.

Wang, Z. and Englund, P. T. (2001). RNA interference of a trypanosome topoisomerase II causes progressive loss of mitochondrial DNA. European Molecular Biology Organization fournal 20, 4674-4683.

Ward, C.P., Burgess, K.E., Burchmore, R. J., Barrett, M.P. and de Koning, H.P. (2010). A fluorescence-based assay for the uptake of CPD0801 (DB829) by African trypanosomes. Molecular and Biochemical Parasitology 174, 145-149.

Wenzler, T., Boykin, D. W., Ismail, M. A., Hall, J. E., Tidwell, R. R. and Brun, R. (2009). New treatment option for second-stage African sleeping sickness: in vitro and in vivo efficacy of aza analogs of DB289. Antimicrobial Agents and Chemotherapy 53, 4185-4192.

Werbovetz, K. A. (2006). Diamidines as antitrypanosomal, antileishmanial and antimalarial agents. Current Opinion in Investigational Drugs 7, 147-157.

Wilson, W. D., Tanious, F.A., Buczak, H., Venkatramanan, M. K., Das, B. P. and Boykin, D. W. (1990). The effects of ligand structure on binding mode and specificity in the interaction of unfused aromatic cations with DNA. In The Ferusalem Symposia on Quantum Chemistry and 
Biochemistry (ed. Pulman, B. and Jortner, J.), 23 331-353. Kluwer Academic Publishers, Dordrecht, the Netherlands.

Wilson, W. D., Nguyen, B., Tanious, F. A., Mathis, A., Hall, J. E., Stephens, C. E. and Boykin, D. W. (2005). Dications that target the DNA minor groove: compound design and preparation, DNA interactions, cellular distribution and biological activity. Current Medicinal Chemistry Anti-Cancer Agents 5, 389-408.

Wilson, W. D., Tanious, F. A., Mathis, A., Tevis, D., Hall, J. E. and

Boykin, D. W. (2008). Antiparasitic compounds that target DNA. Biochimie 90, 999-1014.

World Health Organization (2010). Control of the Leishmaniasis. WHO Technical Report Series No. 949. World Health Organization, Geneva, Switzerland.
Zhou, L., Lee, K., Thaker, D. R., Boykin, D. W., Tidwell, R. R. and Hall, J. E. (2002). Enhanced permeability of the antimicrobial agent 2,5-bis(4-amidinophenyl)furan across Caco-2 cell monolayers via its methylamidoidme prodrug. Pharmaceutical Research 19, 1689-1695.

Zhu, X., Liu, Q., Yang, S., Parman, T., Green, C., Mirsalis, J., Soeiro, M.N., de Souza, E. M., da Batista, C.F., da Gama Jaen Batista, D., Stephens, C. E., Banerjee, M., Abdelbasset Farahat, A. A. Munde, M., Wilson, W.D., Boykin, D.W., Wang, M.Z. and Werbovetz, K. (2012). Evaluation of arylimidamides DB1955 and DB1960 as candidates against visceral Leishmaniasis and Chagas Disease - in vivo efficacy, acute toxicity, pharmacokinetics and toxicology studies. Antimicrobial Agents and Chemotherapy 56, 3690-3699. 